\title{
Los procesos de institucionalización del agua en la Provincia de Salta. El caso de Cerrillos (Provincia de Salta) entre 1901 y 1921
}

Daniel Medardo Ontivero*

Cuadernos de Historia. Serie economía y sociedad, N²6/27, 2021, pp. 103 a 146.

RECIBIDO: 01/09/2020. EVALUADO: 18/03/2021. ACEPTADO: 10/05/2021.

\section{Resumen}

El objetivo de la investigación es estudiar el proceso de institucionalización del agua dado entre 1901 hasta 1921 en el Departamento de Cerrillos, para lo cual se avanzará con el análisis del marco regulatorio dado en dicho período, teniendo en cuenta las dinámicas locales en relación con la aplicación del mismo. Ello, nos permitirá interiorizarnos en las diferentes acciones llevadas a cabo por el estado provincial respecto al manejo del agua, aportando referencias sobre un período que se caracteriza por un vacío historiográfico. Por otra parte, nos centraremos en un enfoque regional con perspectiva local, permitiendo comprender las razones por las que, si bien dicho proceso se inició a principios del siglo XX, recién pudo concluirse con el Código de Aguas provincial (1946).

Palabras claves: institucionalización del agua - legislación - Cerrillos

\section{Summary}

The objective of the research is to study the process of institutionalization of water from 1901 to 1921 in the Department of Cerrillos, for which the analysis of the regulatory framework given in said period will be advanced, taking into account the local dynamics in relation to the application of it. This will allow us to gain insight into the different actions carried out by the provincial state regarding water management, providing references about a period characterized by a historiographic gap. On the other hand, we will focus on a regional approach with a local perspective, allowing us to understand the reasons why, although this process began at the beginning of the 20th century, it could only be concluded with the provincial Water Code (1946).

* Universidad Nacional de Salta. E-mail: cerrilloscultura@gmail.com 
Keywords: institutionalization of water - legislation - Cerrillos

\section{Introducción}

A lo largo de la segunda mitad del siglo XIX, en América Latina se plantearon una serie de procesos, tantos políticos (mayor centralización) como económicos (desarrollo del capitalismo agrario), que confluyeron en la institucionalización del manejo de las aguas. ${ }^{1}$ La misma significó la ejecución de acciones concretas, en las que si bien las instituciones estatales surgidas en el seno de una creciente modernización fueron aplicando pautas y principios reguladores respecto al manejo del agua, se tuvieron que enfrentar a escenarios conflictivos que pocas veces favorecieron las intervenciones oficiales condicionando sus resultados. En el caso de Argentina, se dieron similares procesos debido a que los estados provinciales comenzaron a centralizar el manejo y la distribución de las aguas con propósitos económicos. ${ }^{2}$ Sin embargo dicha centralización resultó ser difícil dado que previamente se tuvieron que dar diversas condiciones, principalmente aquellas de naturaleza jurídica y legislativa en las que los dueños de las aguas - que estaban a favor del dominio del agua en carácter privado y que no querían perder sus privilegios y fueros coloniales - cedieran sus derechos a los estados provinciales. Debido a ello, tanto en América Latina como en Argentina los procesos de institucionalización resultaron ser complejos, debido a que se tuvieron que enfrentar a múltiples actores y grupos sociales que participaron en relaciones de conflictos y colaboración con dichos procesos, llevando a cuestionar el orden estatal con pretensiones de imponer unidireccionalmente sus políticas. Esto último nos lleva a pensar que el orden estatal no fue uniforme, sino que se "...fragmenta en agencias dependientes de jurisdicciones diversas y superpuestas, que se corporiza en sujetos insertos en múltiples vinculos sociales y se juegan en cada uno de esos hechos su coherencia, consistencia y los rasgos que definen su estatitad...".

1 Véase Aguirre González, Palerm Viqueira \& Montes Hernández, 2010, Castañeda González, 2004, Gómez Serrano, 2013, Osorio, 2004, entre otros.

2 Miranda, 2009, Martín, Rojas \& Saldo, 2010, Genini, 2000, Comba, 2007, Rossi \& Bandazo, 2016, Tasso, 2003-2004.

3 Ortiz Borgia, 2015: 60. 
En el caso de la Provincia de Salta, los intentos por centralizar el agua se manifestaron a lo largo de la segunda mitad del siglo XIX en un contexto de municipalización territorial dado que fue desde esas unidades administrativas, conocidas como municipios, desde donde se plantearon acciones tendientes hacia la estatización. Es así que, frente a una situación explosiva de conflictos entre usuarios por el incremento de la frontera agraria, surgieron los primeros intentos por reglamentar el uso del agua. Particularmente en el Valle de Lerma y de Siancas esta era administrada y distribuida, mediante reglamentos y ordenanzas, por las autoridades locales concentradas en los Concejos Municipales. Su administración se dio con cierta discrecionalidad y generalmente no se atendieron los intereses de todos los que requirieron agua, debido a que los integrantes de los Concejos Municipales fueron en su mayoría propietarios de las fincas y de las acequias. Ello, sin embargo, no eximió a que el Poder Ejecutivo provincial tomara intervención en cuestiones de uso y aprovechamiento del agua para riego, aunque sin resultados efectivos en términos políticos y legislativos que favorecieran la promulgación de una ley provincial de aguas. Esta recién comenzará a discutirse a principios del siglo XX aunque sin el resultado esperado dado que los propietarios de las tierras y aguas, instalados en espacios de poder local y provincial retardaron los procesos de centralización del recurso hídrico que comenzará a ser considerado como estratégico para la provincia.

Teniendo en cuenta lo dicho, el objetivo de la presente investigación es estudiar el proceso de institucionalización del agua dado entre 1901 hasta 1921 en el Departamento de Cerrillos, para lo cual se analizarán las regulaciones dadas en dicho período. Ello nos permitirá interiorizarnos no sólo en las diferentes acciones llevadas a cabo por las agencias estatales con el objetivo del traspaso del agua en sus manos sino también en las diversas reacciones surgidas a propósito de estas demostrando a través del estudio de un caso, el carácter complejo, intrincado, inacabado, heterodoxo y conflictivo de la estructuración del Estado en el país. ${ }^{4}$ Este último aspecto resulta interesante, debido a que nos permitirá introducirnos en las discusiones teóricas que se fundamentan en los procesos de formación estatal y en los problemas que este atravesó en la adquisición de nuevas competencias estatales. Como se evidenciará más

4 Ortíz Bergia 2015: 6. 
adelante, la imposición de nuevas relaciones de dominación sobre otras, muchas veces terminaron siendo impugnadas por el accionar de diversos agentes que moldearon las políticas públicas de acuerdo a sus propios intereses. Ello motiva a que tratemos al estado provincial no como un actor unívoco, es decir como aquel que impuso sus políticas públicas de carácter coercitivo y unidireccional, sino como un conjunto de organizaciones y actores políticos que definieron la orientación de las políticas públicas en un escenario en permanente disputa entre grupos, corporaciones, actores políticos, etc. Ello significa contribuir con los enfoques que proponen mirar al estado "desde adentro", retomando a diversos autores que se especializan en este tema. ${ }^{5}$ En este sentido, Soprano nos indica que:

una mirada más preocupada por reconocer matices en los procesos históricos, revelaría que el Estado también puede comprenderse como una institución más bien heterodoxa y bastante menos eficaz en su pretensión de ejercer monopolio legítimo de la violencia física y simbólica sobre una población inscripta en un territorio ${ }^{6}$

En términos analíticos, se ha decidido estudiar el caso del Departamento de Cerrillos debido a la posición estratégica que ocupaba en el Valle de Lerma en relación al circuito ganadero que se dirigía a las salitreras del Norte chileno. Dado que nuestra área de estudio, junto con otras del Valle de Lerma y Calchaquí, contaba con las condiciones óptimas para el engorde del ganado vacuno, esta se fue especializando en tal actividad. Ello provocó una serie de transformaciones agrarias materializadas en la ampliación de la frontera agrícola y en la demanda de agua para riego destinada a la producción de alimento para el ganado vacuno proveniente del Chaco salteño. Como es de suponer, dichas transformaciones, motivadas también por el crecimiento de la población, fueron promotoras de un escenario de conflictividad en la que intervinieron diversas agencias estatales y los diferentes actores sociales que estuvieron interesados por el control del recurso hídrico. De este escenario de conflictos también participaron los dueños de las fincas del Departamento vecino de Rosario de Lerma, ${ }^{7}$ quienes al estar interesados por el recurso hídrico hicieron del problema uno de carácter interjurisdiccional debido a

5 Bohoslavsky \& Soprano 2010, Soprano 2008, Ortiz Borgia 2015, entre otros.

6 Soprano, 2007: 20.

7 Rosario de Lerma es una localidad del noroeste de Argentina, en la Provincia de Salta. Es cabecera del departamento homónimo, y se encuentra a $35 \mathrm{~km}$ de la Ciudad de Salta, capital de la provincia. 
que el espacio hídrico era de uso compartido. Sin embargo, hemos optado por el caso de Cerrillos debido no sólo por su posición central en el Valle de Lerma, sino por una amplia disponibilidad de diversas fuentes documentales redactadas en este período, lo cual hizo factible la obtención de resultados que hicieron más productiva la presente investigación. Por tal motivo, este estudio de caso nos permitirá no sólo indagar sobre algunas de las facetas de las complejidades que se esconden detrás de los procesos de institucionalización del agua en la Provincia de Salta, sino además avanzar en los difíciles procesos que llevaron a la construcción de estatidad aportando referencias respecto a las reacciones e impactos locales como el caso cerrillano. Es decir que nos permitirá reconocer los sentidos plurales que forman parte de los procesos de institucionalización debido a la intermediación de diversos actores localizados dentro y fuera del ámbito estatal. ${ }^{8}$

Respecto al período tomado como referencia, se justifica debido a las evidencias de intentos por una mayor centralización provincial manifestada a partir del Código Rural de 1903 hasta la renuncia del Gobernador Joaquín Castellanos hacia 1921. Con la misma, se producirá la derogación de un primer acto fallido de Ley de Irrigación ( $n^{\circ}$ 1.636) basado en los principios del Código Civil (1869). Ello posibilitó que los sectores hegemónicos, llamados en el ámbito político como "conservadores", continuaran controlando el agua en la provincia y que la discusión alrededor de una ley de irrigación quede pospuesta por el momento.

Para terminar, podemos encuadrar los resultados de esta investigación en la corriente historiográfica que está preocupada por considerar al Estado no como una entidad "singular" sino "plural", que se fragmenta en agencias dependientes de jurisdicciones diversas y superpuestas y toma cuerpo a través de las interacciones de diversos agentes sociales que recrean las políticas públicas de acuerdo a sus intereses y objetivos particulares. ${ }^{9}$ Para ello, se apela al tratamiento de fuentes de diversas naturaleza que nos permiten una comprobación empírica del objetivo propuesto, intentando llenar el déficit de conocimiento que existe en la región sobre dos temas: a) los procesos de institucionalización del manejo del agua y b) aquellos referidos a la formación estatal.

8 Soprano, 2007: 20.

9 Soprano, 2007, Bohoslavsky \& Soprano 2010. 


\section{Estado de la cuestión}

En estos últimos años en América Latina, el tema del regadío se ha abordado en función de preguntas de investigación específicas y desde perspectivas teóricas que han permitido responder diversos interrogantes. Así, por ejemplo, se avanzó con excelentes resultados en la comprensión de la relación "Riego, Estado y Poder" considerando, en general, que el Estado y los regímenes que ha reproducido - con sus respectivas alianzas -, se han construido y fortalecido en función del control y la mediación de la gestión y de los usos del recurso en diferentes escalas del orden social. Dentro de ese contexto de innovaciones teórico metodológicas, los conflictos en torno a los usos sociales del agua también se han estudiado desde concepciones teóricas diversas y, casi siempre, en su interrelación con el uso social de otros recursos, en particular la tierra. ${ }^{10}$ Así, las propuestas teórico-metodológicas se orientan a considerar a las relaciones sociales de confrontación también como constitutivas de las de poder.

Además del interés por establecer la interrelación entre "comunidad organizada" y "riego", los estudios comenzaron a centrarse sobre el modo de como los regantes administraban y manejaban el agua. En ese sentido, se han realizado contribuciones significativas sobre la capacidad técnica y el manejo social del agua de riego llevada a cabo por las comunidades. ${ }^{11}$ Dentro de esa vertiente, la preocupación se basa en la forma de organización del riego. Allí, Palerm Viquiera ha llamado la atención sobre los niveles organizativos (comunitario y multicomunitario) ${ }^{12}$ y “.... sobre la administración y el manejo del sistema de riego asumida por los propios regantes y/o por el estado en uno u otro nivel organizativo...". ${ }^{13}$ Es precisamente desde ese enfoque donde se centra nuestra investigación que pretende, a partir del estudio de las legislaciones que acompañan a los procesos de institucionalización del agua, aportar conocimiento a la faz organizativa de los sistemas de riego en la Provincia de Salta. De la interrelación entre organización

10 Millón, Hall \& Díaz, 1997, Oré Vélez, 2005, Kauffer, 2010, entre otros.

11 Castañeda González, 2004, Aguirre González, Palerm Viqueira \& Montes Hernández, 2010, Kauffer Michel, 2010, Escobar Ohmstede, 2013, Gómez Serrano, 2013, entre otros.

12 Palerm Viquiera, 2000.

13 Mazabel, 2007: 204. 
del manejo del agua y la legislación (reglamentos, ordenanzas, códigos, leyes, etc.) sobre esta, es posible arribar al conocimiento de cómo se organizaron los usuarios, dándole a estas formas organizativas de naturaleza reglamentaria un carácter de historicidad al ser consideradas como parte de un proceso de institucionalización del agua a nivel provincial.

En la Argentina, es de reciente preocupación recuperar la dimensión histórica de los sistemas de riego dado que hubo un predominio de investigaciones que se han dedicado tan solo al régimen jurídico del agua. Estos trabajos juegan un papel muy importante debido a que brindan datos sobre los procesos que han llevado a la institucionalización del manejo del agua hacia el interior del país.

De una revisión sobre las investigaciones que nos podrían aproximar a antecedentes para este estudio, debemos decir que los trabajos que comienzan a destacarse son aquellos que analizan no sólo la evolución del manejo del agua desde una perspectiva jurídica, sino que incorporan otras variables tales como las económicas, sociales y políticas. Así por ejemplo es el caso de Guillermo Genini, ${ }^{14}$ quien analiza la relación entre el riego y la legislación en San Juan durante la segunda mitad del siglo XIX y los primeros años del siglo XX. Éste analiza la legislación del agua porque considera que es un elemento "revelador" de otras relaciones económicas, sociales y políticas que es necesario "descubrir".

Otro trabajo interesante es el realizado por Aníbal Comba para Tucumán en una publicación denominada "Historias (pocos conocidas) del agua en Tucumán”. Allí, en el prólogo se destaca la calidad de "pionera" de la obra dentro de la comunidad hídrica. Tal como se puede leer: "... logra ensamblar el tema del agua en sus circunstancias de espacio, tiempo y lugar, articulando la influencia de las acciones bumanas en los aspectos relativos a las decisiones politicas, convicciones y capacidad de gestión de generaciones pasadas...". 15 Situado desde una perspectiva histórica que remonta a la época de la fundación de Tucumán, el autor centra su interés en los procesos que han llevado a la institucionalización del agua. Para él, el período que comprende la segunda mitad del siglo XIX y principios del siglo XX

14 Genini, 2000.

15 Comba, 2007: 3. 
representa un hito histórico en materia de manejo del agua y de construcción de la infraestructura básica para su aprovechamiento en Tucumán.

Para el caso mendocino, Martín, Rojas \& Saldi en "Domar el agua para gobernar"16 también aportan una interesante perspectiva desde la Ecología Política, en tanto indagan sobre los proyectos hegemónicos provinciales acerca de la distribución del agua y del espacio desde finales del siglo XIX y principios del XX. Al interior del trabajo retoman una serie de normas destinadas a administrar el recurso hídrico. Como es de suponer, las mismas confluirán en una Ley de Aguas (1884) que, junto a los organismos que se crearon para su administración, permitirán la reconversión productiva de finales del siglo XIX.

Para Salta, es la investigación de Atilio Cornejo ${ }^{17}$ nuestro antecedente más próximo, aunque su perspectiva no se centra en lo histórico sino en el régimen político. A pesar de que el autor califica su propio estudio como “... una ligera investigación...” significa por el contrario un verdadero avance al conocimiento de la problemática del agua en Salta que, según él y coincidiendo con un autor más contemporáneo como Miranda que analiza la situación en Mendoza, ${ }^{18}$ se le había prestado escasa atención en nuestro país. ${ }^{19} \mathrm{El}$ tratamiento que hace Cornejo está respaldado de un bagaje de documentos históricos y legislativos (entre ellos reglamentos y ordenanzas) que se extiende desde el período colonial hasta fines del siglo $\mathrm{XX}$ y sirven de referencia para futuras investigaciones sobre el tema. Según el autor, lo que inspira su trabajo fue la necesidad de "llenar las lagunas" en lo que atañe al tema del derecho de agua.

Como se advertirá, todo estudio basado en la cuestión hídrica en la Provincia de Salta debe basarse ineludiblemente en los trabajos realizados por Atilio Cornejo, dada la exhaustiva profundización que realiza de los marcos jurídicos y la introducción a algunas problemáticas planteadas en torno al dominio del agua (institucionalización) por parte de los regantes y el Estado. Sin embargo, en estos últimos años se han venido desarrollando una serie de investigaciones sobre este tema, aunque acotadas al período de finales del siglo XIX y principios del XX. Entre ellos citaremos, los realizados por

16 Martín, Rojas \& Saldi, 2019.

17 Cornejo, 1980.

18 Miranda, 2009.

19 Cornejo, 1980: 68. 
Diego Ashur ${ }^{20}$ y Adolfo Saravia, ${ }^{21}$ quienes nos abren la perspectiva para nuevas investigaciones que darán paso a la comprensión de los procesos de institucionalización del agua en Salta.

Fuera de la provincia, resultan importantes los aportes que realiza Hernández Aparicio respecto al riego y los procesos de institucionalización en la región de los Valles Centrales de la Provincia de Jujuy, llamando la atención sobre la carencia de estudios sobre el tema en la región del norte argentino. ${ }^{22}$

Por lo analizado, si bien existe una prolífica cantidad de investigaciones referidas al problema del agua en América Latina, es un tema de investigación reciente en nuestra área de estudio, particularmente, en lo que se refiere a la organización de los regantes y a los procesos de institucionalización llevados a cabo por el estado local y provincial. Por tal razón, la propuesta de un estudio que pretende explicar los procesos organizativos referidos al manejo del recurso hídrico en el Departamento de Cerrillos resulta innovador por los escasos avances que, en términos historiográficos, se vinieron llevando a cabo hasta el momento.

\section{Características del espacio geográfico e hidráulico}

Situado en el Valle de Lerma (ver mapa $n^{\circ}$ 1), el Departamento de Cerrillos tiene una superficie de $25 \mathrm{~km}^{2}$, siendo el menos extenso de la provincia. Su extensión de sur a norte es de 39 kilómetros y de este a oeste de 33 kilómetros aproximadamente. Sus límites actuales son el río de Sumalao por el sur y Río Ancho por el norte. Las cumbres del Cerro de la Pedrera, por el este, y los campos del Pucará por el oeste. Sus coordenadas geográficas, lo ubican entre los $65^{\circ} 15^{\prime}$ y $65^{\circ} 39^{\prime}$ de longitud oeste y los $24^{\circ} 52^{\prime}$ y $25^{\circ} 8^{\prime}$ de longitud sur. Limita al norte y este con el departamento Capital, al sur con Chicoana y al oeste con el departamento de Rosario de Lerma.

20 Ashur, 2004.

21 Saravia, 2000.

22 Hernández Aparicio, 2020: 192. 


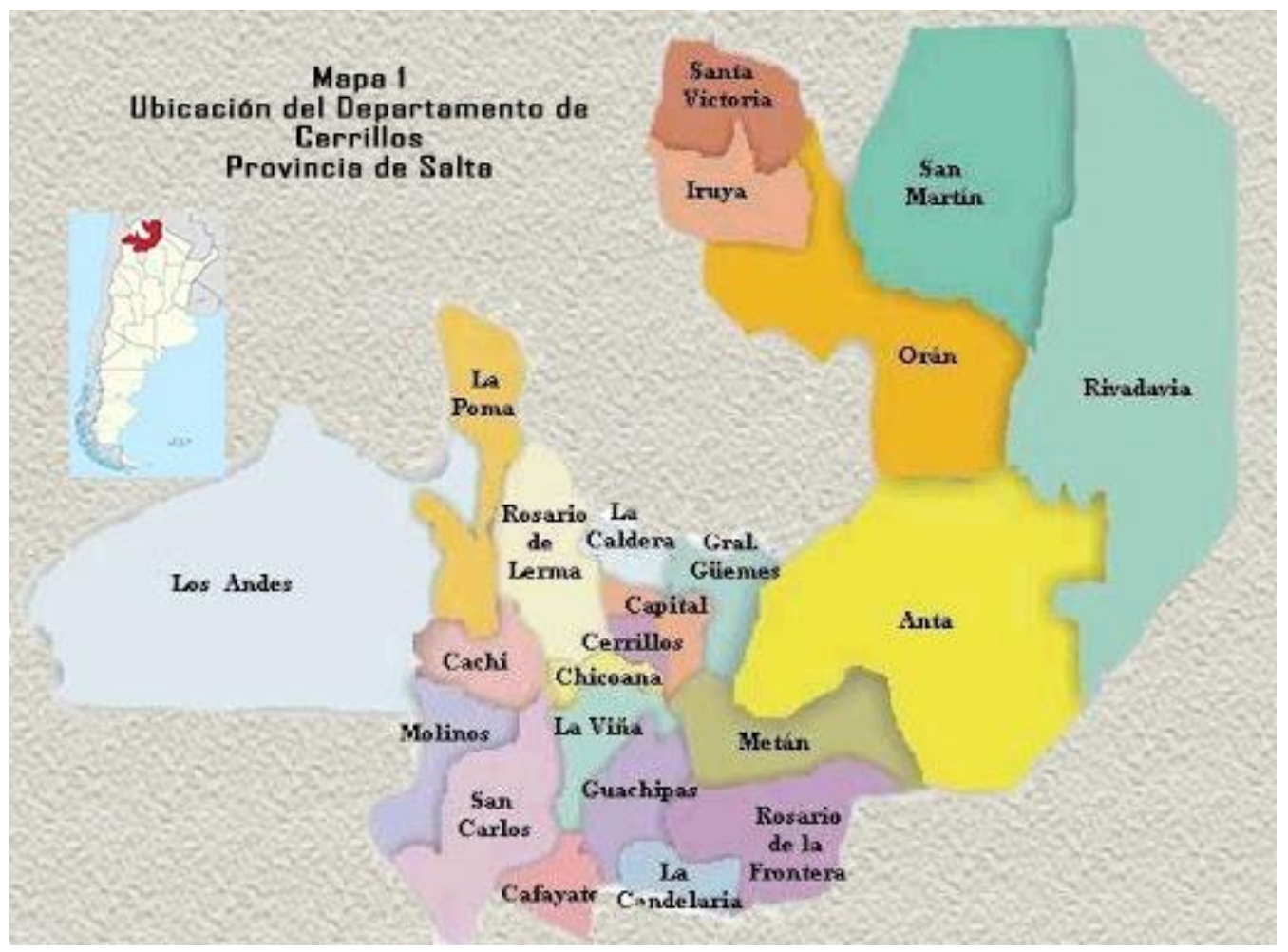

Mapa 1

De acuerdo a los informes de la segunda mitad del siglo XIX, el departamento estuvo vinculado con una red caminera que la unía a los valles Calchaquíes, por lo que se constituía, al igual que en la actualidad, en un lugar estratégico dado que era un paso ineludible. Su importancia también estaba dada porque presentaba un notable crecimiento en el aspecto urbano y poblacional. Teniendo en cuenta la Memoria Descriptiva de Manuel Solá publicada hacia 1887, Cerrillos era una población llena de comercio y actividad:

tiene una bonita plaza, iglesia, casa Municipal, Botica, escuela para varones y escuela para niñas, oficina telegráfica y telefónica, almacenes, tiendas y pulperías. En sus alrededores hay importantes establecimientos industriales, tales como el gran molino italiano de Cánepa y la finca que fue de los Naveas, y a las dos leguas, San Agustin y La Isla, pero luchas por la escasez. del agua mal distribuida... Sus habitantes se dedican principalmente a las sementeras de cereales y alfalfares, últimamente ensayan con plantaciones de vida ${ }^{23}$

23 Solá, 1889: 408. 
De acuerdo a sus datos, en este período existían 325 propiedades y 314 propietarios, dueños de unidades de producción de diferente naturaleza: estancias, fincas, chacras y quintas que poseían diferentes dimensiones y orientaciones productivas que iban desde la ganadería hasta la agricultura. Además de estas, también se desarrollaban otras actividades económicas tales como la extracción de cal, que abastecían a las obras de construcción en la Capital y a los departamentos vecinos.

En un informe enviado al Gobernador de la provincia por la Comisión Municipal hacia 1889, Cerrillos aparecía descripto en similares términos. Se hacía énfasis en el florecimiento urbano del pueblo, rasgo que lo distinguía frente a otros cercanos. ${ }^{24}$ Pero dicho crecimiento urbano no era el único manifestado en el departamento: iguales consideraciones son las expresadas para el caso de La Merced - pueblo ubicado al sur de este - y del denominado el Bordo de San Agustín en las proximidades de Sumalao. ${ }^{25}$ Tanto el crecimiento urbano como poblacional de estos pequeños poblados fueron los signos que evidenciaron un florecimiento inusitado dado en el Departamento entre finales del siglo XIX y principios del XX que trajo como consecuencia la proliferación de diversas políticas legislativas provinciales y locales, alrededor del mejoramiento en la infraestructura urbanística y caminera, en la educación, en el accionar sanitario y en el manejo de una política fiscal acorde al crecimiento económico en términos de modernidad.

En lo que respecta a la caracterización del espacio hidráulico departamental, son los informes de gobierno los que generalmente nos dan una impresión del mismo. Así, un informe ${ }^{26}$ nos indica que la valoración sobre la situación hídrica en el departamento es relativa, dado que trata solo de la parte en la que el agua lograba llegar, lo cual nos permite constatar que el sistema de regadío no llegaba a cubrir a la totalidad del territorio agrícola. En la parte que lo hacía, el agua que se destinaba para el riego era provista desde bocatomas - estructuras hidráulicas destinadas a derivar el agua desde el río Toro. Estas captaban el agua y la distribuían a través de un sistema de acequias

24 Archivo Histórico Municipal de Cerrillos (de aquí en adelante A.H.M.C), Actas del Concejo Municipal. Informe enviado al Sr. Gobernador por la Comisión Municipal sobre la conveniencia del lugar donde se debería de construir la estación del ferrocarril. 19 de febrero de 1889.

25 A.H.M.C., Actas del Concejo Municipal. Informe enviado al Sr. Gobernador por la Comisión Municipal sobre la conveniencia del lugar donde se debería de construir la estación del ferrocarril. 19 de febrero de 1889.

26 A.H.M.C, Actas del Concejo Municipal. Informe que presenta la Municipalidad del Departamento de Cerrillos al Gobierno de la provincia conforme Decreto de fecha 25 de agosto de 1894. 
(canales de diversas dimensiones), que tenían su origen en el río de la Quebrada del Toro, ${ }^{27}$ ubicado en el actual Departamento de Rosario de Lerma ${ }^{28}$ y en la parte más elevada del espacio hidráulico compuesto por ambos departamentos (Cerrillos y Rosario de Lerma).

Con el volumen de agua proveniente de estas acequias se disponía de agua para una superficie aproximada de $300 \mathrm{~km}^{2}$, distribuidos en los Partidos de Cerrillos, San Miguel, la Candelaria, Belgrano, San Agustín, la Merced y Colón (ver mapa no 2).

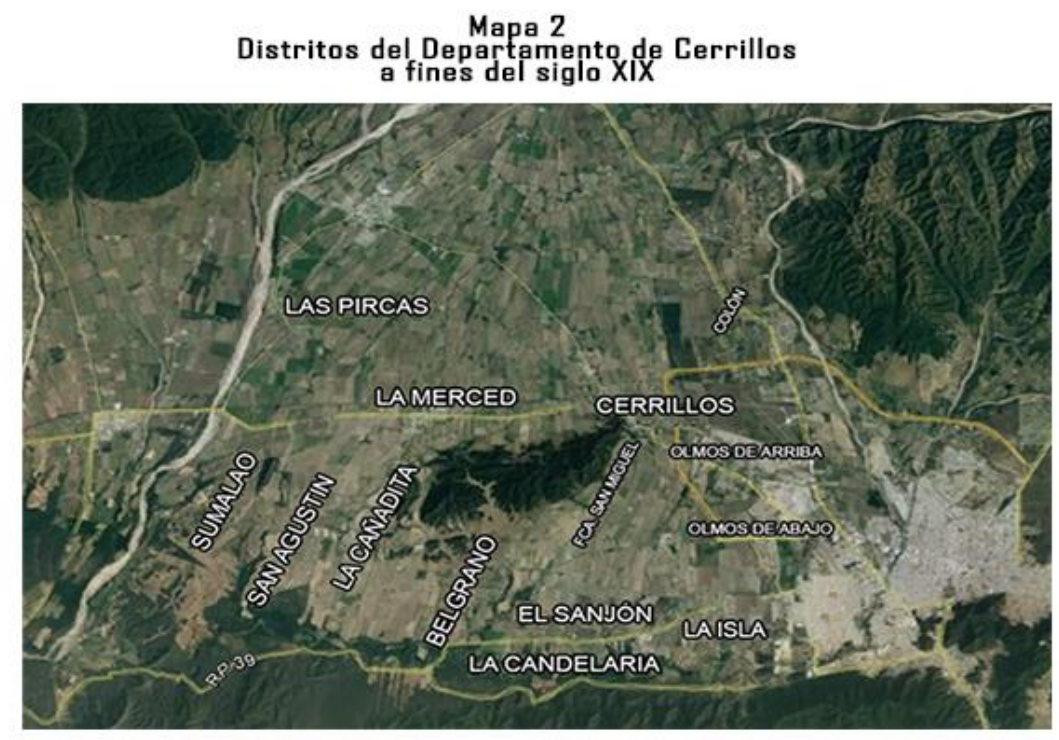

Fuente: Elaboración propia

El escrito es interesante a la hora de definir las características del espacio hídrico, dado que nos aporta datos de los distritos, su potencialidad en términos de la producción y las limitaciones con relación al acceso al agua. En general, el departamento presentaba óptimas condiciones para el desarrollo de la agricultura debido al clima que caracteriza al Valle de Lerma, aunque con ciertas restricciones de acceso al agua para riego. Por tal razón, la infraestructura de riego que existía jugó un papel importantísimo para el

27 La Quebrada del Toro, es un accidente geográfico (quebrada) ubicado entre la localidad de Campo Quijano (1521 m) y Puerta Tastil, en el Departamento Rosario de Lerma, Provincia de Salta.

28 Hacia 1899, el Departamento de Rosario de Lerma confinaba al norte con la provincia de Jujuy por el arroyo de las Burras, al este con el departamento de Cerrillos por el camino de Pulares y la acequia de la Silleta, al sud con el de Chicoana por el arroyo que corría hacia Punta Diamante y el camino de Pulares y al oeste con el departamento Capital por las cumbres de San Lorenzo y con el Caldera por el Nevado del Castillo, véase Latzina, 1899: 571. 
desarrollo de una agricultura en crecimiento. Sin embargo, a pesar del papel jugado por dicha infraestructura, en lo referido al abastecimiento del agua (restringido, por cierto), encontramos que este estuvo supeditado a una serie de limitaciones provocadas por razones técnicas y geográficas (ubicación de la cuenca hídrica). Respecto a la parte técnica, por ejemplo, la posición de la fuente de agua resultaba un hecho decisivo para el abastecimiento de la misma, por la distancia que debía recorrer hasta llegar a los campos cerrillanos. Por otra parte, dado que la fuente de agua se ubicaba en Rosario de Lerma, su posición geográfica se convirtió en el centro de las discusiones debido a los constantes reclamos por las diversas prácticas sociales (hurto, desvío, etc.) que provocaban la escasez de la misma. Estas fueron llevadas a cabo principalmente por los propietarios del distrito de Rosario de Lerma y de la Silleta (perteneciente al departamento rosarino), quienes no escatimaron en el ejercicio de cortar el agua de acuerdo a sus necesidades:

Hoy se abre una nueva acequia, mañana se tranca toda el agua por otras, pasado se comete otra arbitrariedad por arrenderos, regadores, etc. y no hay poder bumano que contenga esos abusos. De aqui que el Departamento de Cerrillos si no va a grandes pasos en decadencia, pronto será un hecho en desgracia ${ }^{29}$

Esta referencia resulta relevante para entender la razón por la que la posición de la cuenca hídrica y sus ciclos hídricos resultaron ser factores que condicionaron el acceso regular del agua de riego en la parte de abajo del espacio hidráulico y un caldo de cultivo para generar la escasez del agua en Cerrillos. Es así que frente a un incremento de la frontera agraria y a la conformación de nuevas jurisdicciones municipales (Municipio de la Silleta) se produjeron una serie de conflictos en torno al dominio del agua. ${ }^{30} \mathrm{Tal}$ situación será motivo de discusiones por el agua que no se resolverán tan fácilmente sino hasta la manifestación de procesos de centralización hídrica. En este sentido con la aparición del Código Rural de 1881 y con la creación de la Oficina Topográfica, de Estadística e Irrigación (1884), ${ }^{31}$ se inició un proceso de institucionalización provincial,

29 A.H.M.C., Actas del Concejo Municipal. Informe que presenta la Municipalidad del Departamento de Cerrillos al Gobierno de la provincia conforme Decreto de fecha 25 de agosto de 1894.

30 Ontivero, 2019a.

31 En la sección 4ta. del Reglamento de la Oficina Topográfica, de Estadísticas e Irrigación, se mencionaba sobre las atribuciones del Departamento de Irrigación que entendería en todo lo relativo a la distribución de las aguas y obras hidráulicas indispensables para su aprovechamiento, véase Ley $n^{\circ} 73$ de Creación de la Oficina Topográfica, de Estadísticas e Irrigación (7 de mayo de 1884). 
que a nivel departamental repercutirá con la conformación del Sindicato de Aguas $(1886)^{32}$ compuesto por los principales propietarios de tierras. Al respecto, si bien hubo una mayor intervención del estado provincial en los asuntos del agua, la misma no será tan eficaz dado que desde los Concejos Municipales los grupos locales de poder salieron a la defensa de sus intereses.

\section{Antecedentes de los marcos regulatorios sobre la gestión y administración del agua}

Con la abolición del Cabildo de Justicia y Regimiento de la ciudad de Salta hacia 1825, todo lo relativo al agua quedó bajo la esfera del Poder Ejecutivo provincial “...aunque respetando las prerrogativas y facultades de orden municipal..." ${ }^{33}$ Así es que el 11 de julio de 1839, durante el gobierno de Don Manuel Solá se dictó un reglamento sobre aguas, en el que se establecían disposiciones referentes a los jueces de agua y a una comisión para controlar la actividad de estos. Dos años después, el Gobernador Don Miguel Otero dictó un decreto sobre aguas del río Calchaquí ordenando que desde el $1^{\circ}$ de setiembre hasta fines de diciembre - tiempo en que se experimentaba una escasez de agua - se largaran todas las aguas que no fueran necesarias para el cultivo de las tierras. El 3 de octubre de 1842, por otra parte, apareció un decreto en donde el gobernador Manuel Antonio Saravia y su ministro Dr. Fernando Arias regulaban sobre la distribución de las aguas que provenían desde las acequias del Poniente de la ciudad salteña. Si bien tales medidas constituyen verdaderos antecedentes normativos que sirven a los efectos de situarnos sobre la legislación provincial de aguas durante la primera mitad del siglo XIX, ${ }^{34}$ hay que decir que a nivel local el manejo de estas estuvo en manos de los propios regantes quienes, desde normativas coloniales, controlaron y distribuyeron las aguas de acuerdo a intereses familiares. En el caso de Cerrillos, la

32 El Sindicato de aguas del Departamento de Cerrillos fue creado el 31 de julio de 1886. Si bien fue impulsada desde el órgano político local, también fue el resultado de sugerencias y demandas de los vecinos propietarios de las tierras y acequias. Este sirvió, aunque a nivel embrionario, a los efectos de una centralización local de la gestión del agua. Véase Ontivero, 2018: 33.

33 Cornejo, 1980: 83.

34 Cornejo, 1947: 46-47. 
situación descripta anteriormente se dará con características similares; estando el agua en manos de algunas familias propietarias de las acequias.

Sin embargo, con la creación del Municipio hacia 1857 se comenzará un proceso que llevará a una mayor intervención del Concejo Municipal en aspectos referidos al agua. Ello será impulsado desde el Reglamento de Municipalidades de 1856, desde donde se hará hincapié en las funciones del municipio en lo atinente al arreglo y la distribución de las aguas. ${ }^{35}$ A diferencia de los Códigos Rurales (1881, 1884 y 1903) y Orgánicas de Municipalidades que aparecerán más adelante, en el Reglamento se hacía énfasis en la distribución de las aguas teniendo en cuenta sólo los títulos de propiedad, es decir, que las atribuciones del estado local estarían orientadas tan sólo a regular la distribución del agua de acuerdo a la infraestructura de riego existente, respetando los derechos adquiridos sobre el recurso hídrico. Con ello, si bien se inicia la municipalización del manejo del agua, el hecho de que se reconocieran los derechos adquiridos de los propietarios de las acequias hizo que por el momento no se plantearan discusiones sobre el dominio del agua debido a que no significaba la pérdida de los privilegios sobre el control de la misma. Dichas discusiones se plantearán con el Código Civil (1869) cuando en este se estableciera el principio que consideraba al agua como un bien público. Dicho Reglamento también dio instrucciones respecto a la conformación de reglamentos de aguas en cada localidad, situación que se manifestó desde fines de la década de 1860 en el Valle de Siancas y de Lerma. ${ }^{36}$ De acuerdo a lo expuesto, es evidente que este corpus reglamentario representa un primer avance con fines de ordenamiento de las aguas llevado a cabo por el estado local.

Más adelante, con la Constitución provincial de 1875 se continúa en la misma dirección. Se estipulaba, aunque de manera escueta, que una de las atribuciones inherentes al régimen municipal estaba referida al "servicio y distribución de las aguas"." Asimismo, los Códigos Rurales de los años 1881, 1884 y 1903 trataban sobre el dominio y aprovechamiento del agua, dando especificaciones respecto a las facultades

35 “Reglamento de Municipalidades para la Provincia de Salta (1856)”, en Gabino Ojeda, 1929.

36 Véase Reglamentos de Aguas del Departamento de Campo Santo (1867), de Cerrillos (1869) y de Chicoana (1874).

37 Constitución de la Provincia de Salta (Sancionada el 27 de enero de 1875) en Gabino Ojeda, 1929. 
que tenía el municipio en la reglamentación del agua. ${ }^{38}$ Particularmente en el Código Rural de 1881 quedaba expresada la función municipal referida a la concesión del aprovechamiento del agua. Sobre el dominio público de las aguas, el Código señalaba que el agua de riego para uso y dominio público era de los "particulares individual y colectivamente considerados", tan pronto se salía de su cauce natural para entrar a otro particular.

En el Código Rural de 1881, al igual que el de 1884 que lo reemplazaría, se avanzó en la organización, administración y gestión del agua en los distritos agrícolas. Es por ello que se promovió la conformación de una comunidad de regantes (en el resto de Latinoamérica conocido como "Juntas de Aguas"39), la cual estaría sujeta a reglamentos de riego elaborados por el municipio a los propósitos del servicio y distribución del agua. Se indicaba que dicha comunidad de regantes, conocida como "Sindicatos de Aguas", estaría compuesta por los vecinos más honorables. De acuerdo al Código, el Sindicato no era un organismo autónomo dado que dependía del Concejo Municipal y sólo debía atenerse a la ejecución de las reglamentaciones. Dado que la condición para acceder al Sindicato era la de ser productor agrícola, la composición del mismo estuvo determinada por intereses corporativos desde un primer momento. En este sentido, es difícil pensar el funcionamiento de los Sindicatos como totalmente alejados de los intereses del grupo terrateniente, quienes también estuvieron vinculados al Concejo Municipal. De allí que, no debe resultar extraña la presencia de los grandes propietarios en instituciones como estas dado que, desde esos sitios, comenzaron a intervenir con el propósito de retener los privilegios y los fueros coloniales que habían logrado alrededor de las cuestiones hídricas. Es así que, por ejemplo, en el Reglamento para el Sindicato se dispuso que las atribuciones de este fueran la defensa de los intereses de la comunidad de los regantes. ${ }^{40}$

El proyecto del Código Rural de 1884, por otra parte, fue formulado por los señores Dr. Eliseo F. Outes, Robustiano Patrón Costas y Alejandro Figueroa. De acuerdo a las referencias de Atilio Cornejo, el Título III trataba sobre el dominio y aprovechamiento de las aguas y estaba dividido en 29 secciones. Las prescripciones

38 Cornejo, 1980: 93.

39 Palerm Viqueira, 2003.

40 “Código Rural de la Provincia de Salta (arreglado el año 1881)”, en Gabino Ojeda, 1929. 
del código fueron las mismas del código rural anterior y reflejaba el interés de la provincia por el problema del agua. Tal como lo dice Cornejo, es interesante destacar "...la intervención que en algunos casos que se les da a las municipalidades; lo mismo que respecto de las concesiones al Gobierno y hasta a los jueces de Pazy a la Dirección de Obras Públicas...". ${ }^{41}$ Del código, también llama la atención la importancia que se le seguía asignando a los derechos adquiridos por los propietarios en relación al uso del agua y al protagonismo de los Concejos Municipales a la hora de dirigir sus observaciones a la provincia.

El Código Rural de 1903 que derogaba el de 1884 resultó de mejor elaboración en lo que se refería al tema de la distribución de las aguas. Respecto a cuál sería la institución encargada de la tarea de la distribución, al igual que los códigos anteriores se señaló recaería en las Municipalidades "en todo lo que no afecte el derecho de propiedad". ${ }^{2}$ En el título 15, por ejemplo, se avanzó sobre las prerrogativas del municipio como responsable de la concesión de las aguas que eran consideradas de dominio público. Como se advierte, el régimen de aguas fue de carácter eminentemente municipal, por lo que el ordenamiento de las aguas para riego se concentró en manos del Concejo Municipal. En este sentido, hay que señalar, que esta municipalización del manejo de las aguas siempre estuvo en concordancia con la Leyes Orgánicas de Municipalidades. Así, por ejemplo, en la Ley Orgánica n 239 promulgada en 1889, se establecía que era tarea del municipio el servicio y distribución de las aguas de riego de uso común, a efecto de lo cual estaba facultado a la emisión de reglamentos de irrigación que fuesen necesarios. En referencia al dominio del agua, esta ley hacía una clara distinción entre las aguas de regadío de uso común y aquellas de uso por derecho propio, aclarando hasta que se definiera una "ley general de irrigación". ${ }^{43}$ De manera similar, en la Ley $\mathrm{n}^{\circ}$ 563 Orgánica de Municipalidades, promulgada en diciembre de 1898, se refería el tema de la siguiente manera:

son atribuciones de la Municipalidad: arreglar convenientemente el servicio y distribución de las aguas de regadio de uso común en el Municipio, dictando al efecto los reglamentos de irrigación que fuesen necesarios. Entiéndase por agua de

41 Cornejo, 1980: 91.

42 "Código Rural de la Provincia de Salta (1903)", en Gabino Ojeda, 1929.

43 “Ley n 239 Orgánica de Municipalidades (1889)”, en Gabino Ojeda, 1929. 
regadio de uso común aquellas que no sean del dominio particular por derecho propio y mientras se dicte una ley general de irrigación ${ }^{44}$

Es síntesis, durante la segunda mitad del siglo XIX, el proceso de institucionalización del agua fue llevado a cabo por el estado local y se fue logrando de manera gradual, aunque muchas veces, como lo veremos más adelante, estuvo supeditado a complejos procesos de resistencia de parte de diversos sectores que estuvieron interesados por el control hídrico. Mediante disputas entre las élites de Cerrillos y Rosario de Lerma, ya sea de manera individual o desde instituciones como el Concejo Municipal, se promovió una situación de tensiones y conflictos que se comenzó a vislumbrar con relación a una mayor demanda del agua para riego respondiendo a los efectos de una reorientación económica con el propósito de cubrir las demandas del mercado del salitre en Chile. Son varios los ejemplos que denotan dichas tensiones y conflictos, entre los más importantes podemos mencionar un juicio entre los municipios de Cerrillos y Rosario de Lerma dado entre 1869 y 1881 y casos de expedientes judiciales que remontan a actitudes de regantes en relación al no cumplimiento del nuevo orden estatal de naturaleza municipal. ${ }^{45}$

Para terminar, el proceso que llevará a la institucionalización del agua fue orientado a través de un corpus regulatorio compuesto por Códigos Rurales (1881, 1884 y 1903), las Leyes Orgánicas de Municipalidades (1888 y 1898) e inclusive las Constituciones, que sirvieron de base a los efectos de un ordenamiento de las aguas. Sin embargo, si bien anteriormente habíamos indicado que en la Constitución de 1875 se hacía referencia a la distribución de las aguas como función del municipio, destacamos que el tema del agua fue progresivamente desapareciendo en la letra de las Constituciones. En la Constitución de 1885, por ejemplo, no hay mayores referencias sobre el tema del manejo del agua a excepción de sólo la frase "servicio y distribución de las aguas" junto a otras atribuciones municipales que significaban mayor injerencia. En las Constituciones siguientes, la del año 1888 y la reformada de 1906, el tema de agua

44 “Ley n 563 Orgánica de Municipalidades (1898)", en Gabino Ojeda, 1929.

45 Véase Importante sentencia en el asunto sobre agua entre Cerrillos y Rosario de Lerma (1905). Dictado el 5 de junio de 1882 (Imprenta el Comercio de R.R. Sanmillán y Cia, Salta) y "Causa CCXXVII: Don José Ramón Navea con la Municipalidad de Rosario de Lerma sobre interdicto de recobrar y retener la posesión" en Fallos de la Suprema Corte de la Justicia nacional con la relación de sus respectivas causas (1869). Publicación realizada por los Doctores Don Nemecio Rojo y Don Antonio Tarnasi (secretarios del Tribunal). Tomo IV (Imprenta de Pablo E. Coni, Buenos Aires). 
estuvo ausente. ${ }^{46}$ Allí, no aparece el tema hídrico como una atribución inherente al municipio sino de la provincia. Este tema recién se hará visible en la Constitución de 1949, cuando en esta se refiriera al régimen de las aguas públicas. ${ }^{47}$

El hecho de que en las constituciones provinciales desaparecieran articulados específicos donde se atribuían al municipio el manejo del agua, pudo haber respondido a dos razones. La primera: al resultado de los procesos políticos que llevaron a un interés por la centralización del estado provincial, en donde el tema del agua pasaría a depender principalmente de este a través de normativas e instituciones creadas para tal fin. En este sentido, una prueba de dicha centralización queda demostrada en el interés de parte de la provincia en aspectos relacionados con obras de irrigación en el Valle de Lerma; el ejemplo que sobresale es el estudio que se le encargó al Ing. Carlos Wauters en 1908 a los efectos de mejorar la distribución del agua a través de mejoras en la infraestructura de riego (construcción de canales, diques, etc.) en el Valle de Lerma. ${ }^{48}$ La segunda, en cambio, responde al hecho de que desde el gobierno provincial se intentó parar las irregularidades que se cometían en los Concejos Municipales. Dado que en estos órganos se concentraban las élites locales, eran propensos a generar un ambiente de inequidad respecto de la distribución de las aguas. Sobre este tema nuevamente Cornejo nos arroja luz, para lo cual cita el mensaje del Gobernador de la Provincia Dr. Martín Gabriel Güemes al abrirse las sesiones de las Cámaras Legislativas en el año 1886:

nuestra Constitución reformada quitó a las Municipalidades la facultad de reglamentar y distribuir el agua de regadío en vista de los abusos que éstas cometian. Hoy no existen autoridades que velen por su árbitro del más fuerte, sirviendo asi a los intereses de unos pocos en perjuicio de la generalidad ${ }^{49}$

La situación descripta no nos resulta extraña dado que en otras investigaciones similares ${ }^{50}$ hemos podido constatar los problemas y las estrategias surgidas entre las

46 "Constitución de la provincia de Salta de 1906 (Reformada por la Convención Constituyente)", en Gabino Ojeda, 1929.

47 Cornejo, 1980: 94.

48 "Ley n ${ }^{\circ}$ 796. Aprobando el contrato celebrado entre el Gobierno de la Provincia y el Ingeniero Don Carlos Wauters sobre estudios de irrigación en el Valle de Lerma”, en Gabino Ojeda, 1929.

49 "Mensaje del Gobernador de la provincia de Salta Dr. Martín Gabriel Güemes al abrirse las sesiones de las Cámaras Legislativas (1886)", citado en Cornejo, 1980.

50 Ontivero, 2019b. 
élites de Cerrillos y Rosario de Lerma en torno al control del agua y que respondieron a las diversas resistencias de parte de estas a un nuevo orden social. Los daños y perjuicios, reflejados en constantes reclamos por algunos regantes, provocaron una situación de tensiones y conflictos que retardaron los procesos de institucionalización llevados a cabo desde provincia. En este sentido, es evidente que si bien pareciera que la aplicación e imposición de instituciones y normativas alrededor del agua fueron de carácter uniforme y centralizada, la realidad demuestra que no fue así debido a los desafíos y desobediencias frente a los intentos de gobernabilidad.

De esa situación estuvieron atentos los gobiernos provinciales a través de sus diversas gestiones, por lo que las respuestas se fueron dando de manera gradual a través de diversas disposiciones legales sobre el agua. A tal efecto, se tuvo que avanzar sobre los poderes locales mediante un marco regulatorio sobre un tema tan estratégico como el agua, dado que desde el pensamiento provincial era el promotor del desarrollo agrario del Valle de Lerma. Sin embargo, la aplicación de dichos marcos regulatorios no resultó del todo fácil debido a que se tuvo que enfrentar a un escenario de disputas por el agua, en la que diversos actores sociales formaron parte de un complejo escenario político que desafiaban las normas previstas desde el Estado. De allí, concluimos que los alcances de esta investigación no sólo deben estar orientada hacia la mera descripción de las normativas que pudieron llevar a la institucionalización del agua, sino establecer si las mismas efectivamente fueron cumplidas.

\section{Los marcos normativos en el período 1903- 1921: ¿camino hacia una institucionalización provincial?}

Como se ha dicho, la inicial institucionalización del agua resultó de la formulación de marcos normativos y de su correspondiente aplicación, aunque es oportuno señalar que las mismas no estuvieron ajenas de problemas debido a que la comunidad de regantes tuvo una actitud de cumplirlos de manera efectiva. Esta última, se justificaría por la defensa de los intereses corporativos vinculados con el dominio de las aguas en carácter privado, demostrando que las agencias estatales tuvieron problemas en hacer que sus intervenciones fueran efectivas. De este modo, los diversos casos de juicios 
contra el estado municipal de Rosario de Lerma o aquellos entre los propios dueños de las acequias, las denuncias de incumplimiento de las tareas asignadas a burócratas del agua o el pedido de una Ley de Irrigación de carácter provincial son evidencias de la intervención efectiva y cotidiana, en la producción de la estatalidad a nivel local tal como lo señala Soprano en relación a otro tema. ${ }^{51}$ De ese tema, nos vamos a dedicar en las próximas páginas.

En lo que respecta a los marcos regulatorios - que no deben ser considerados como legislación de aguas - planteados para principios del siglo XX, el inicio del proceso se dio con el Código Rural de 1903. Como se advierte de la lectura del mismo, el código establecía que cada municipalidad debía reglamentar el uso del agua. Asimismo, tal cual como sucediera con los códigos anteriores, el énfasis estuvo puesto en el reconocimiento de los derechos adquiridos de los dueños de las acequias hasta que se dictara una ley general de irrigación. ${ }^{52}$ Esta posición política de respetar los derechos adquiridos, sin embargo, comenzará a discutirse a medida que el estado provincial intentara tomar control de las aguas. Un ejemplo de ello es el Proyecto de Ley de Irrigación de 1901, presentado por el Dr. Julio Cornejo y que fuera rechazado por la Cámara de Diputados. El justificativo de tal decisión se fundamentó en el hecho de que, entre sus considerandos se avanzaba sobre el principio de las aguas como públicas.

Unos años más tarde y a partir del código mencionado, surgió a instancia del gobierno provincial la "Ordenanza General de la distribución de las aguas de la Quebrada del Toro" de 1914. Esta fue presentada por los delegados de los Concejos Municipales de Cerrillos, de Rosario de Lerma, de La Merced y de la Silleta y elevada al Ministro de Gobierno Dr. Julio Cornejo bajo la gobernación del Dr. Robustiano Patrón Costas. Tal cual como se lee al final de la ordenanza, esta fue enviada por el vicepresidente de la Comisión Municipal de Rosario de Lerma, Don Adolfo Diez, en acuerdo con el presidente de la Comisión Municipal de Cerrillos, Don César Cánepa Villar, con el presidente de la Comisión de La Merced, Don Rudecindo Alvarado, y con el presidente del Concejo de La Silleta, Don Lucas Vidal.

51 Soprano, 2007: 41.

52 Cornejo, 1980: 93. 
La ordenanza constaba de VI Capítulos y 27 artículos. La primera disposición que se establecía en el documento se trataba del nombramiento de cuatro comisiones municipales que se harían cargo, aunque circunstancialmente, de la distribución del agua de la Quebrada del Toro. Lo interesante de la mencionada disposición (artículo $1^{\circ}$ ) y de allí lo circunstancial, es que confirma lo dicho anteriormente respecto a indicios de una mayor injerencia del Poder Ejecutivo en la cuestión hídrica:

Los representantes de las cuatro comisiones municipales durarán en sus funciones hasta que el Poder Ejecutivo de la Provincia, en cumplimiento de lo convenido y en virtud de la ley respectiva se haga cargo definitivamente de la distribución de las aguas de la Quebrada del Toro ${ }^{53}$

Con la cita queda demostrada cual fue la orientación de la política hídrica planteada por la provincia en ese momento. Ello significó el diseño de políticas orientadas hacia una mayor intervención provincial en una cuestión que hasta décadas recientes les había pertenecido a los municipios. De allí que se fue cristalizando el interés de la provincia y de la nación por el control de las aguas, llevando a que los Concejos Municipales perdieran una cierta autonomía en las decisiones referidas al manejo de la distribución de las aguas.

En términos generales, la Ordenanza era una expresión de una creciente organización del tema del reparto de las aguas entre los departamentos de Cerrillos y Rosario de Lerma y el estado provincial. Es así que, a través de sus considerandos, se advierten indicios del traspaso del manejo del agua a provincia, aunque ello no significa que se hubieran aplicado de manera efectiva. Un aspecto que se destaca en la letra, por ejemplo, es que la renovación de las autoridades del Tribunal Superior estaría en manos de las autoridades provinciales. ${ }^{54}$

En este sentido, la Ordenanza no sólo nos aporta datos importantes respecto a la distribución de las aguas entre los departamentos de Cerrillos y Rosario de Lerma sino que nos permite corroborar, al menos en su formulación teórica, la situación de avance de la provincia en cuestiones normativas que habían sido de mayor injerencia para el

53 “Ordenanza General de la Distribución de las Aguas de la Quebrada del Toro (1914)", en Gabino Ojeda, 1929. El subrayado es nuestro.

54 A.H.M.C., Actas de Oficios, 1902-1919. Nota enviada al Ministro de Gobierno provincial Rafael Zuviría a los efectos de que se nombre autoridades para la distribución del agua, 15 de abril de 1917. 
estado local. Es así que el problema del riego se convertirá en un motivo de futuras disputas políticas por el agua, que se verán reflejadas en las sucesivas intervenciones políticas realizadas a la provincia desde 1918 por el presidente Hipólito Yrigoyen. ${ }^{55}$ Además de los conflictos entre nación y provincia, tales intervenciones pondrán al descubierto la confrontación de intereses entre la provincia abocada a la centralización y al avance sobre el principio del derecho público de las aguas y los dueños de la tierra y aguas que pretendían conservar su status quo mediante el reconocimiento del derecho privado de las aguas. Así, producto de la primera intervención provincial, en la que había sido designado el Dr. Emilio Giménez Zapiola, se decidió crear el Tribunal de Aguas (creado por Decreto $n^{\circ}$ 48) con el propósito de ordenar la distribución del agua a nivel provincial. La misma estuvo fundada en:

la conveniencia de reglamentar en la mejor forma posible todo lo relativo a la distribución de las aguas en la Provincia, y teniendo en cuenta que mientras no exista una ley que provea y resuelva las exigencias que el servicio de irrigación requiere y considerando que a falta de un decreto orgánico que no es posible dictar sin un estudio detenido de las necesidades de cada departamento y de las disposiciones existentes en cada Municipalidad de acuerdo con los dispuesto en el art. 16 inc. 5 de la ley respectiva, es el caso de proveer de inmediato a salvar siquiera sea provisoriamente esa situación a todas luces deficiente, dada la importancia que para la explotación rural reviste el problema que acaba de enunciarse $^{56}$

El objetivo de la creación del Tribunal se concentraría en: a) el estudio de la situación de la reglamentación de las aguas en todos los municipios, b) tomar conocimientos de las quejas que se presentasen sobre la distribución de las aguas, c) tomar nota de los conflictos interdepartamentales y d) presentar un proyecto de decreto reglamentario provisorio y un proyecto de ley para que sirviera de base a la reglamentación definitiva. ${ }^{57}$

El Dr. Manuel Carlés fue el sucesor de Giménez Zapiola en la intervención de la provincia en 1918. Este elevó un interesante informe al Ministerio del Interior en donde se refería al tema de la irrigación. Haciendo énfasis en los antecedentes del riego

55 Cornejo, 1980: 107.

56 Giménez Zapiola, 1918: 147.

57 Cornejo, 1980: 108 
dividió la historia del riego en la provincia en tres partes: a) guerra por el agua, ${ }^{58}$ b) justicia del agua ${ }^{59}$ y c) paz del agua. ${ }^{60}$

Las apreciaciones del informe resultan importantes por dos razones: por un lado porque nos brinda ideas sobre la situación hídrica a nivel provincial y por otro porque, a pesar de que relativiza la eficacia del Tribunal de aguas creado por Zapiola, consideraba que para dar solución a la "guerra del agua" era necesaria la creación de una legislación que fuera eficiente dado que la anterior era todo lo contrario. Sin embargo, de acuerdo a Cornejo hubo actitudes de su parte en donde más que avance se procuró una continuidad de la situación hídrica a favor de los dueños de las tierras. Una evidencia de ello es un decreto dictado por Carlés (el 16 de agosto de 1918) autorizando a los comisionados municipales de Rosario de Lerma, Cerrillos, La Silleta y La Merced a proceder, de común acuerdo, en todo lo referente al reparto equitativo y justo de las aguas del río Toro. Dicha autorización, como se puede advertir, iba en contra de los intentos por centralizar el agua en manos de la provincia y demuestra que el Interventor volvía “... a las andanzas de las antiguas costumbres y de la deficiente legislación existente que no fue, realmente, destruida, sino más bien dicho su interrupción actualizada...". 61

Luego de esta intervención y fruto de elecciones a gobernador, el Dr. Joaquín Castellanos asumió el cargo el 7 de enero de 1919. Su gestión se caracterizó por desafiar a la hegemonía de los sectores conservadores que gobernaban la provincia. Además de exigir una ley que regulara los recíprocos derechos y deberes de los propietarios de tierras y de los trabajadores, Castellanos proponía, por ejemplo, un nuevo régimen de aguas. Ello, junto a otros factores, produjo una situación de

58 De acuerdo con el Interventor, el origen de los pleitos se situaba en los privilegios que habían adquiridos algunos regantes dado el acceso al agua por mercedes de agua. Esta situación de derecho adquirido se transformó en un problema dado el incremento de la población, la sucesión y consecuente desmembramiento de las grandes propiedades y el aumento de la frontera agraria. Tales características fueron motivo para que se comenzara a demandar una mayor cantidad de agua de regadío por lo que se generó una "guerra del agua" en la que intervenían los "dueños del agua" por derechos adquiridos y los nuevos agricultores que avanzaban sobre tierras vírgenes a favor de la agricultura.

59 La "Justicia del agua": comenzaría con el ensayo de una legislación de aguas pensada a partir de la Intervención Nacional.

$60 \mathrm{La}$ "Paz del agua", a decir de Carlés, se refiere a aquella etapa que inicie la Legislatura de la provincia con la sanción atinada y científica del sistema económico de la distribución del agua, de acuerdo con las necesidades agropecuarias del trabajo y de las industrias locales.

61 Cornejo, 1980: 109. 
inestabilidad política dado que produjo una fuerte oposición de parte de los senadores alineados en la Unión Provincial, quienes renunciaron a sus bancas. Como es de suponer, el tratamiento específico de esta ley si bien pudo significar un paso hacia una más equitativa distribución de los derechos sobre el uso de las aguas, por el otro implicó la intervención y la conservación de la hegemonía de los dueños de las aguas instalados en el poder político. ${ }^{62}$

Este nuevo régimen que tomó cuerpo en la Ley n 1.033 - número original 1.036 -, se tituló "Del aprovechamiento del agua pública para la provincia de Salta" ${ }^{33}$ Los antecedentes de esta, como lo mencionáramos anteriormente, fue un Proyecto de Aguas de Salta del año 1901, en la que reconocía que las aguas y arroyos pertenecían al dominio público. Este proyecto redactado por el Ministro de Gobierno Dr. Julio Cornejo, que resulta ser un primer intento de subordinación del dominio privado al público, fue rechazado. ${ }^{64}$ En uno de sus considerandos, se hablaba sobre el dominio público del uso del agua de los ríos y arroyos de la provincia y sobre el derecho que los particulares tenían adquiridos. ${ }^{65}$ De igual naturaleza fue la Ley $\mathrm{n}^{\circ} 1.033$, siendo sus principales principios aquellos relacionados con la inherencia absoluta del agua al suelo, reiteración sobre que sus normas estaban basadas en el Código Civil (1869) en donde se reconocía el dominio del agua como pública, aunque sin olvidarse de los derechos adquiridos, entre otras. ${ }^{66}$

Tanto la de 1901 como la de 1919 quedaron en la nada y sólo se constituyeron como antecedentes de una futura de Ley de Irrigación que saldría a la luz décadas más tarde. De acuerdo con Figueroa, la Intervención Federal derogó la ley impulsada por Castellanos "....sin siquiera dictar un instrumento legal alguno que así lo disponga...". 67

En síntesis, la cuestión hídrica, además del enrarecido clima político de la época debido a las intervenciones anteriores y las críticas de la prensa al gobernador Castellanos, fue uno de los factores que alteró la política a nivel provincial llevando inclusive a que

62 Saravia, 2000: 63-70.

63 "Ley n 1033 (Número original 1636) De aprovechamiento del agua pública para la Provincia de Salta", en Gabino Ojeda, 1929.

64 Figueroa, 2017: 1.

65 Cornejo, 1980: 117.

66 Figueroa, 2017: 3.

67 Figueroa, 2017: 3. 
fuera intervenida en ese mismo año. A decir de Saravia ${ }^{68}$ en relación a la Ley de Riego, al hacerse referencia sobre el hecho de que el dominio del estado sobre el agua no reconocía otra limitación que la establecida por la ley, traía como secuela la derogación de los derechos adquiridos por los propietarios. Como es dable pensar, estos últimos se terminarían alineando en una estrategia política (renuncia a sus bancadas y vacío de poder) con el propósito de lograr la intervención del gobierno, evitando la concreción de una ley que los afectaba hegemónicamente. Al respecto, en una carta enviada a Hipólito Yrigoyen, Castellanos decía sobre estos:

El partido local, más que cualquier otro, merece la denominación de "conservador", toda vez que si con todas sus fuerzas profesan sinceramente dicha ideología, lo es para conservar sus prerrogativas con las cuales sus principales componentes ejercitan modos señoriales en sus propiedades como grandes dueños de la tierra, dueños incluso del agua estatal, árbitros del trabajo y del destino de los arrendatarios, y hasta de sus conciencias toda vez que ejercen la coerción moral de los ricos patrones sobre los pobres agricultores ${ }^{69}$

A través de lo expuesto, queda corroborada la idea de que frente a un proceso de institucionalización del agua a nivel provincial, que es evidente, hubo otros procesos de resistencias y disputas dados en la arena política por parte de los sectores dueños de las tierras y aguas. Posicionados en el poder político, si bien estos pudieron haber acompañado a los procesos de institucionalización provincial lo hicieron en la medida que estos no afectaran las bases económicas que los sustentaban hegemónicamente. Esto último demuestra las alteraciones por las que tuvieron que atravesar las nuevas formas de orden estatal en respuesta al accionar de las élites que desafiaron a las autoridades estatales. En este sentido, siguiendo las ideas de Bohoslasvky \& Godoy Orellana: ${ }^{70} \quad$ “... estas prácticas no fueron naturales, obvias, necesarias ni estructuralmente determinadas sino el resultado de decisiones, reflexiones y cálculos asumidos...” por los diferentes actores sociales.

A continuación, nos vamos a introducir en una realidad micro analítica, tratando de dilucidar los alcances de los procesos de institucionalización en el contexto del

68 Saravia, 2000.

69 "Carta abierta enviada por el Dr. Joaquín Castellanos al presidente Hipólito Yrigoyen (1921)”, citado por Saravia, 2000: 69-70.

70 Bohoslasvky \& Godoy Orellana, 2008: 5. 
Departamento de Cerrillos. Es a partir de esa posibilidad que vamos a poder interiorizarnos en los cambios que se pudieron haber dado alrededor del manejo del agua para riego y en los procesos de resistencia frente a los intentos de instauración de un nuevo orden estatal.

\section{El inicio inacabado del traspaso de la distribución de las aguas para riego a la provincia: el caso cerrillano}

El análisis de los códigos, reglamentos y leyes durante este período resulta fundamental porque nos permite entender las coyunturas organizativas en torno a la distribución del agua y a los procesos que han llevado a su institucionalización en manos de la provincia. Sin embargo, uno de los aspectos que no fue tratado, por el momento, se refiere a las instancias que dieron a nivel local y que permitieron el traspaso de las atribuciones que recaían en los municipios respecto al manejo del agua hacia la provincia. Este proceso se lo puede rastrear en los diferentes escritos de la época y constituyen el principal argumento para pensar que las causas se las debe buscar no sólo en las políticas del estado provincial sino también en el contexto político y económico local. Por tal razón, en el presente apartado seguiremos algunos indicios sobre la cuestión hídrica y la situación del municipio de Cerrillos frente a los primeros intentos de traspaso de la distribución de las aguas a la provincia, haciendo la aclaración que dichos intentos no fueron unidireccionales sino todo lo contrario, puesto que se dieron en el marco de un proceso complejo de resistencias, consensos y adaptaciones de parte de las agencias estatales, de diversos actores sociales en relación al nuevo orden estatal. Para ello, tomaremos como base a dos documentos que nos permitirán comprender el tema. Uno de ellos, se trata de la intervención de la provincia en "el reparo y extracción del agua de las bocas tomas en el Río Toro" de 1904, y, el otro, de las instancias legislativas que dieron como origen la ordenanza: "Distribución de las Aguas de la Quebrada del Toro" de 1914.

Respecto al primero, se trata de una nota enviada el 16 de julio 1904 al Ministro de Gobierno de la provincia. Allí, una comisión compuesta por presidentes de las 
Municipalidades de Cerrillos, La Merced, la Silleta y Rosario de Lerma le adjuntaban un acuerdo en el que también había participado el Gobernador David Ovejero. En la nota, que llevaba el n ${ }^{\circ} 344$, se pedía al Departamento Topográfico de la provincia se determinara la mejor forma de reparo de las boca-tomas del Río Toro. Asimismo, se pedía que un Juez repartidor de aguas desviara el agua del río, precisamente por el costado del lugar donde se repararían las boca-tomas a efectos de evitar desperfectos. También, por otra parte, se había acordado con el Departamento Topográfico de la provincia la realización de estudios necesarios a efectos de determinar:

la mejor forma para que el agua de las diversas acequias sea extraída por las bocatomas existentes en el reparo, salvando los inconvenientes que el efecto se oponen boy ${ }^{71}$

La nota es un indicio de cómo la provincia, a través del Departamento Topográfico, había comenzado a inmiscuirse en aspectos técnicos de las obras hidráulicas locales. Hasta ese entonces, dichas acciones habían sido injerencia de los dueños de las acequias y del municipio. Por otra parte, la nota indica sobre una creciente presencia del estado provincial en asuntos relativos al agua, estableciendo de manera homogénea directrices en común respecto al tema hídrico.

Antes de avanzar con el segundo documento haremos alusión a un escrito formulado por Emilio Schlech ${ }^{72}$ en el que menciona las características de la irrigación en la provincia hacia 1914. Adentrarnos en un texto como el señalado se justifica a efecto de tener referencias exactas sobre la situación hídrica en general. Es así que, para Schlech apenas existían algunas obras de irrigación en construcción frente a una serie de proyectos que no habían logrado hacerse efectivos. Dada esta situación, los canales y acequias no llegaban a cubrir la demanda de agua requerida, por lo que se mantenía estancado el “...progreso agrícola y la producción del suelo...”.

En relación con lo dicho por Schlech, aparecían dos preocupaciones. Primeramente, la mayor demanda de agua implicó mayor presión de parte de los regantes sobre un sistema de riego obsoleto. Esto fue motivo, según él, de tensiones y pugnas por el control del agua en la que la élite terrateniente resultaba ser la única beneficiada debido

71 A.H.M.C., Actas del Concejo Municipal. Nota enviada al Ministro de Gobierno de la provincia a efectos del reparo y extracción del agua por las boca-tomas en el Río Toro. Año: 1904.

72 Schlech, 1914. 
a su capacidad de movilización en la arena política. De esa situación, el gobierno provincial estuvo al tanto, por lo que desde lo legislativo fue realizando algunas intervenciones respecto al control y manejo del agua, aunque sin éxito alguno en algunas de sus preocupaciones. Si bien la provincia había logrado avanzar en la adopción de mayores atribuciones en el manejo del agua, en relación a los municipios no logró ni superar el obstáculo que tenían algunos regantes en lo que se trataba a los derechos adquiridos, ni sortear las redes económicas y políticas de la que estos formaban parte.

En segundo lugar, sostiene Schlech, desde la provincia se entendía que la manera de ingresar al "ideal de progreso" era a través de una legislación moderna que permitiera el desarrollo capitalista. Sin embargo, para que esto se diera se debía dar previamente una serie de condiciones económicas y políticas, entre ellas: a) una Ley de Irrigación a nivel provincial - que por el momento no sería posible -, b) la resolución del dominio de las aguas a favor de la provincia: esto es, que las aguas fueran públicas, c) una mayor hegemonía sobre aspectos que habían sido concentrados en manos de los Concejos Municipales, etc. Para lograr estas condiciones, ya desde 1910 el Departamento de Obras Públicas había estado pidiendo informes referentes a los derechos del agua como así también respecto al tema de los propietarios de las acequias. ${ }^{73}$

El resultado de estos informes fue que unos años después, hacia 1914, se llegara a la firma de un acuerdo entre los Municipios de Cerrillos y de Rosario de Lerma con el Ejecutivo provincial. En este acuerdo, traducido luego en una Ordenanza - el otro documento analizado -, se advierte un interés de la provincia por el control del recurso hídrico, para lo cual propició - en común acuerdo con los municipios - el traspaso de la distribución del agua, anhelo que ya sido puesto de manifiesto en algunos escritos de la época a los efectos del desarrollo capitalista agrario vigente.

Respecto a las razones de una mayor intervención de la provincia en temas relacionados con el agua de riego, los datos indican que respondieron a los graves problemas que atravesaban los municipios por la mala administración del agua y al interés por la institucionalización del manejo del agua que acompañaría el desarrollo

73 A.H.M.C., Acta de Oficio 1901-1919. Respuesta al Departamento de Obras Públicas respecto a las acequias de Gallo y de Olmos y sobre sus propietarios, 14 de noviembre de 1912. 
agrario. En este sentido, una hipótesis a demostrar está referida a la situación del manejo fiscal municipal como condicionante de la situación hídrica. Si bien no nos hemos abocado de lleno al tema del presupuesto anual del municipio, las evidencias documentales demuestran que este era limitado y que siempre se tuvo que apelar a diversas acciones (empréstitos a vecinos) para poder solventar los gastos de infraestructura y mantenimiento de una burocracia local incipiente.

En el caso del agua para riego, las limitaciones presupuestarias de parte del municipio pudieron haber promovido que hubiera ciertas dificultades a la hora de financiar el manejo de la distribución del agua. Esto se debía al hecho de que además de afrontar las obligaciones propias de un estado local, tales como velar por la infraestructura en general - caminos, puentes, etc. - y garantizar los honorarios de funcionarios administrativos, debía garantizar también la distribución de las aguas y el pago de honorarios a funcionarios que se encargaban de la misma. Por tal razón, las deudas contraídas por el municipio a funcionarios del agua podrían haber sido un factor más que importante a la hora de pensar en las razones de la conveniencia de que determinados aspectos del manejo del agua se traspasaran a la administración provincial. Tal situación, empero, no fue de fácil resolución dada las resistencias llevadas a cabo por los regantes y que fueran desarrolladas en nuestro espacio hidráulico. El hecho de que el agua para riego pasara al Departamento de Obras Públicas pudo significar a los ojos del grupo hegemónico local una pérdida del control del agua. De allí, que el grupo se haya movilizado en función a entorpecer la aplicación de la Ordenanza de Irrigación aprobada hacia 1914. De ello, nos darán evidencias algunos de los casos analizados más adelante.

Lo cierto es que, a través de una resolución, desde la Comisión Municipal, se firmó un contrato con el poder ejecutivo provincial en donde se establecía el traspaso de las atribuciones en torno al riego que recaía en manos del municipio a la provincia. Tal resolución decía lo siguiente:

Art. $1^{\circ}$ : El P. Ejecutivo de la Provincia por intermedio del Departamento de Obras Públicas, tendrá en lo sucesivo a su exclusivo cargo la reglamentación, distribución y reparto de las aguas para regadio del río de la Quebrada del Toro por las acequias denominadas San Agustín, de Arias, de Gallo y de Olmos, asi como el cuidado, la conservación en buen estado y la limpieza de estas mismas acequias, a cuyo efecto las municipalidades contratantes convienen que el $P$. 
Ejecutivo de la Provincia tenga las facultades y atribuciones necesarias para la ejecución de este convenio.

Art. $2^{\circ}:$ El P. Ejecutivo de la Provincia dictará los reglamentos y disposiciones que fueren a su juicio convenientes y necesarios, a la mejor reglamentación, distribución y parto de las aguas de regadio de las acequias indicadas, y al cuidado, conservación y limpieza de estas acequias con sujeción y respeto de los derechos preexistentes de los particulares y de los usos y costumbres sobre esas aguas.

Art. $3^{\circ}$ : El P. Ejecutivo nombrará, sin intervención de las municipalidades, el personal necesario a los fines convenidos y fijará y cobrará los derechos o cuotas que corresponden abonar a los propietarios beneficiarios para el estricto pago de ese personal y de los demás gastos correspondientes a esos fines

Como se advertirá, los artículos del convenio fueron muy claros respecto a las atribuciones que le correspondía a la provincia. Las mismas iban desde la reglamentación hasta la distribución y reparto del agua que habían sido atributos del municipio. Tal fue el recorte de las atribuciones municipales respecto del manejo del recurso hídrico que el Poder Ejecutivo, a través del Departamento de Obras Públicas, aparecía como el único habilitado para el nombramiento de los funcionarios del agua, al menos los de alto rango. Este aspecto es sumamente destacable porque es un claro intento de cercenar la autonomía que gozaba el municipio en lo que se refería al manejo del agua y al nombramiento de algunos funcionarios del agua. Como ya lo habíamos visto anteriormente, en el artículo $n^{\circ} 1$ de la Ordenanza quedaba explícitamente señalada la intención de que la distribución de las aguas quedara en manos de la provincia de manera definitiva, aunque previamente, se debían dar ciertas condiciones legales a través de la conformación de una ley provincial de irrigación. ${ }^{74}$ De esta manera, tanto el manejo del agua y como su administración pasó de manos de los Concejos Municipales a la provincia debido a dos razones. La primera, ya señalada anteriormente, estuvo relacionada con los graves problemas que atravesaban los municipios por la mala administración del agua. Dada la naturaleza de estos problemas, como es razonable pensar, no fueron ajenos a la atención de parte de algunos gobernadores. Dicha apreciación queda corroborada en el mensaje que ya hiciera en 1886 el Gobernador Dr. Martín Gabriel Güemes. En la apertura de las sesiones de las Cámaras Legislativas, hizo alusión a los abusos cometidos por las municipalidades que servían, según él, a algunos intereses en “...desmedro de la

74 Ordenanza General de la Distribución de las Aguas de la Quebrada del Toro (1914), Imprenta Oficial, Salta. 
generalidad..." ${ }^{75}$ La segunda razón, en cambio, tuvo relación con los procesos que llevaron a la consolidación del estado provincial, en la que se promovía no sólo una mayor centralización estatal en desmedro de las autonomías municipales sino una actitud a favor del desarrollo del capitalismo agrario.

El proceso que llevó a que la provincia comenzara a hacerse cargo del tema del agua se inició en los primeros días del mes de enero de 1914 y estuvo, desde un primer momento, supeditado a inconvenientes durante su planteamiento. La ejecución del traspaso de atribuciones a la provincia, se inició mediante un oficio enviado desde el Ejecutivo de la provincia tanto al Departamento de Rosario de Lerma como al de Cerrillos. En virtud de la convocatoria, en una sesión del Concejo se decidió nombrar a los concejales Doctor Don David E. Gudiño, Don José Vázquez Freire y Don Mariano Villa para que asistieran a una reunión en el Ministerio de Gobierno con el propósito de tratar los "asuntos de irrigación, etc. de que se ocupan todas en la actualidad". ${ }^{76} \mathrm{La}$ reunión, estipulada para el día martes de 3 de febrero, preveía la presencia de representantes de La Merced, La Silleta, Rosario de Lerma y Cerrillos. ${ }^{77}$

Resulta interesante destacar, tal cual como lo señaláramos más arriba, que el traspaso de la administración del agua al nivel provincial no se realizó sin dificultades. Significó un proceso de transición que tuvo inconvenientes en el manejo del recurso hídrico. Si bien ésta se realizó con éxito, al menos en términos de encuadre jurídico, a nivel local se comenzaron a advertir ciertos problemas relacionados con la administración del agua, dado que aquellos funcionarios del agua que habían sido puestos en función desde el municipio continuaron con sus tareas a pesar de que las atribuciones sobre el manejo del agua habían recaído en la provincia.

Tal situación queda demostrada por la nota que fuera redactada por Don César Cánepa Villar, presidente de la Comisión Municipal de Cerrillos. En la misma le preguntaba al Sr. Eliseo Cabanillas sobre por qué continuaba ejerciendo actos en carácter de Juez de río de las aguas del río Toro si su cargo había quedado sin efecto.

75 "Mensaje del Gobernador de la provincia de Salta Dr. Martín Gabriel Güemes al abrirse las sesiones de las Cámaras Legislativas (1886)", citado en Cornejo, 1980: 94.

76 A.H.M.C., Actas de Oficio, 1902-1919. Nota enviada al Municipio de Rosario de Lerma por invitación a reunión sobre irrigación, 22 de enero de 1914.

77 A.H.M.C., Actas de Oficio, 1902-1919. Nota enviada al Municipio de La Merced por invitación a reunión sobre irrigación, 30 de enero de 1914. 
Tal pregunta se la hacía creemos que justificadamente dado que el presidente entendía que debido a la "...conferencia que tuvieron los delegados de las Municipalidades del Departamento de Rosario de Lerma, del distrito de La Merced, Silleta y de este Departamento de Cerrillos...",78 todas las autoridades que habían estado a cargo de la administración del agua para riego habían caducado. Por tal motivo, le solicitaba a Cabanillas que se abstuviera del ejercicio de funciones en la distribución del agua, debido a que ese era patrimonio de provincia.

Justamente, el 8 de setiembre de ese año y mediante nota enviada al Ministro General de Gobierno de la provincia Don Julio Cornejo, Cánepa Villar informaba sobre la aprobación de unanimidad del Reglamento General de Irrigación que fuera redactado por los delegados de cada una de las municipalidades y que conformaban la denominada "Junta de Irrigación", cuya presidencia recayó en el Doctor Don David E. Gudiño, ${ }^{79}$ quien hacia 1915 era nombrado nuevamente en dicho cargo. ${ }^{80}$

Como se observa, tales inconvenientes fueron producto de dejar sin efecto las estructuras de gestión y administración del agua que había sido de carácter municipal. Pero también fueron el resultado de las reacciones de los afectados por la política provincial y que se escondían tras de esas personas y tras de esos cargos. Así, otro de los problemas que se hizo evidente con el intento de provincializar el manejo del agua fue la cuestión de la distribución del agua. Eso se notó en un oficio enviado por el Concejo Municipal de Cerrillos al Ministro de Gobierno de la provincia Don Rafael M. Zuviría en donde se solicitaba una reunión entre el gobierno central y de los delegados municipales. Si bien el Concejo reconocía que la Ordenanza General de Irrigación había sido aprobada, era de interés del mismo la modificación de la misma, puesto que observaba que:

las dificultades con que se ha tropesado en su aplicación imposibilitan, tal como está, el normal funcionamiento de la Junta encargada de su aplicación y delicado mecanismo

78 A.H.M.C., Actas de Oficio, 1902-1919. Nota enviada del presidente del Concejo Municipal a Eliseo Cabanillas, 30 de abril de 1914.

79 A.H.M.C., Actas de Oficio, 1902-1919. Nota al Señor Ministro General de Gobierno respecto a la aprobación del Reglamento de Irrigación, 08 de Setiembre de 1914.

80 A.H.M.C., Actas de Oficio, 1902-1919. Nota al concejal Doctor Don David E. Gudiño como representante de la Junta de Irrigación de la municipalidad, 15 de marzo de 1915. 
De acuerdo a la nota firmada por César Cánepa Villar, el problema requería de una rápida intervención debido a lo avanzado de la "estación” (otoño), la falta de lluvias y el mal estado de las acequias. ${ }^{81}$ De la reunión realizada el día 16 de marzo de 1916 se llegó a un acuerdo entre los municipios, aunque sólo en términos formales. Dado que en la práctica eso no sucedió así, se decidió por unanimidad la transferencia del ejercicio de la distribución del agua a manos de la provincia.

En relación con la opinión de los concejales, como esa dependencia iba a necesitar de financiamiento para cubrir las prestaciones de servicio en la distribución del agua, se decidió que cada municipio, de acuerdo al cálculo que les correspondía a los cuatro municipios, entregaría 260 pesos a la provincia. Asimismo, en el oficio se solicitaba, aunque en carácter de "anhelo", que los repartidores deberían ser nombrados por los municipios debido a que: “... ellas conocen a miembros de sus respectivas comunas y podrían encontrar más fácilmente personal adecuado a ese servicio..." 82

Tal solicitud, como se advertirá, escondía la intencionalidad de los propietarios de tierras que ejercían la función pública, debido a que la intervención provincial probablemente les significaba un condicionamiento en el ejercicio del poder sobre la cuestión hídrica. Durante décadas, el nombramiento de los funcionarios del agua se había realizado a través del Concejo Municipal. Ello posibilitaba el control de las aguas a un sector privilegiado de la sociedad, dado que los funcionarios nombrados eran los que distribuían el agua a favor de algunos o en desmedro de otros.

Lo cierto es que la Ordenanza se fue aplicando en cada uno de sus artículos y muchas veces solicitada por los propios Concejos Municipales porque consideraban que al no aplicarse la misma podía verse afectado su acceso al agua. En abril de 1916, en una nota enviada por el presidente de la Comisión Municipal de Cerrillos solicitaba al gobierno de la provincia que la Ordenanza sobre irrigación se cumpliera en todas sus bases y condiciones.

Uno de los requerimientos se refería al pago de la cuota proporcional que correspondía a los municipios favorecidos por la distribución del agua. A los ojos del Concejo

81 A.H.M.C., Actas de Oficio, 1901-1920. Nota enviada por el Concejo Municipal solicitando se modifique la Ordenanza General de Irrigación, 12 de marzo de 1916.

82 A.H.M.C., Actas de Oficio, 1901-1920. Nota enviada al Ministro de Gobierno por el Concejo Municipal reconociendo formalmente el traspaso de la administración del agua, 17 de marzo de 1916. 
Municipal, el pago de la cuota significaba “...prestar un poderoso apoyo al arreglo (por la Ordenanza) para la mejor distribución del agua de la Quebrada del Río Toro...” (el subrayado es nuestro). Cada municipio debía entregar, de acuerdo al agua que le correspondía, una cuota proporcional destinada al pago "... de los empleados encargados de repartir el agua...”. Este aspecto es innovador respecto a la naturaleza de la distribución del agua que se dio en décadas anteriores. Dada esta Ordenanza, el arreglo del agua ya no se daría entre los propietarios de las acequias y el Concejo Municipal sino entre municipios, lo que significó una mayor estatización provincial del manejo de las políticas hídricas.

De todas maneras y a pesar del consenso entre las partes, la Junta de Irrigación advertía serios problemas en la aplicación de la norma, particularmente en lo que se trataba al pago de la cuota. Este era el caso del municipio de Rosario de Lerma, quien no acató lo dispuesto en la Ordenanza de Irrigación. Esta situación, evidentemente, fue el reflejo de los conflictos y las disputas por el agua que existía, desde muy temprano, entre ambos departamentos. Situado en ese período, las disputas por el agua trascenderán el marco interdepartamental y se situará en la lucha por el agua contra los procesos de institucionalización llevados a cabo por la provincia:

la imposibilidad de desempeñar cumplidamente sus funciones, por falta de medios coercitivos para la percepción de los impuestos y más que todo, por no baber cumplido la Comisión Municipal del Rosario de Lerma con el solemne compromiso contraido con las otras corporaciones signatarias de la ordenanza y con P.E. mismo y poner en condiciones a la Junta de percibirlo, de manera que, de las acequias de exclusiva jurisdicción del Rosario de Lerma no ha sido posible absolutamente nada para el pago del persona dependiente de la Junta ${ }^{83}$

En la cita se observa que el mayor inconveniente se dio por la falta de pago del parte del municipio de Rosario de Lerma, lo cual traía como resultado dificultades para hacer funcionar la administración del agua. Como se verá, la situación de desconocimiento a los procesos de institucionalización fue una constante en el caso de Rosario de Lerma, quien a lo largo de las décadas disputó el control por las aguas del río Toro.

83 A.H.M.C., Actas de Oficio, 1902-1919. Nota remitida al Ministro de Gobierno informando respecto de la falta del cumplimiento del pago de la cuota de Agua por parte de Rosario de Lerma, 12 de abril de 1916. 
El ejemplo del incumplimiento en el pago de la cuota del agua por parte del municipio de Rosario de Lerma - compromiso asumido por todos los intervinientes en la Junta de Irrigación -, pone en evidencia que la transición resultó llena de complicaciones y que las tensiones y conflictos tanto departamentales como interdepartamentales estuvieron al orden del día como siempre ocurrió. Esto hizo que desde el municipio de Cerrillos se solicitara en carácter de urgente el cumplimiento del compromiso asumido por parte de Rosario de Lerma, dado que su negativa al pago de la cuota afectaba los intereses "vitales" del departamento por la deficiente distribución del agua. La intención de hacer cumplir la Ordenanza por parte de este municipio no se debía al hecho de que estuvieran de acuerdo con las políticas provinciales respecto al manejo hídrico, sino porque entendía que, a través de la intervención provincial en el tema del acceso al agua se le garantizaría una distribución equitativa de la misma por las razones técnicas y geográficas señaladas más arriba. Con ello, lejos de estar a favor o no de los cambios propuestos en la Ordenanza, desde el Concejo Municipal se sabía que era la única manera de terminar con un largo período de irregularidades en el que los regantes de Rosario de Lerma abusaban de la posición privilegiada que tenían en relación a la fuente de agua. De allí, se entiende que la actitud del municipio de Rosario de Lerma fuera en contra de la aplicación de una Ordenanza que en realidad vendría a poner orden a la situación anárquica de la mala distribución del agua generada por este y por sus propios funcionarios del agua.

Entonces de entre los municipios beneficiados por la aplicación de la Ordenanza tenemos al de Cerrillos. Dada esta posibilidad, en consecuencia, fue el único en intentar cumplir a rajatabla lo establecido. Así se avanzó, por ejemplo, con el nombramiento de "Repartidores de agua", haciendo uso de sus propias atribuciones. Pero el detalle de los inconvenientes no acaba simplemente con los incumplimientos en el pago de cuotas por el agua, también se trasladaron a esferas tales como el de la su distribución. Tanto Bernardo Ibañez como Pedro Franco, repartidores de agua de las acequias de Olmos y Gallo respectivamente, reclamaron ante el Concejo Municipal respecto a "los incorrectos procederes que se observa en el ejercicio de sus funciones" de parte del Juez de reparto Don Telesfor Paz.

En la nota enviada al Ministro de Gobierno de la provincia, Don Rafael Zuviría, se observa que las irregularidades fueron denunciadas por varios beneficiarios del agua 
tales como José Vázquez Freire, Santiago Salinas, Desiderio Aranda, Manuel Delgado, Santiago Jándula, Abel Gaytia e inclusive, el mismo presidente del Concejo Municipal, César Cánepa Villar, quienes hicieron saber a la máxima autoridad respecto de los "abusos e incorrecciones" perpetrados por el mencionado Juez de reparto. ${ }^{84}$

Dada la denuncia, al parecer Don Telesfor Paz fue desplazado de su cargo siendo su reemplazante Don Ceferino Chaile quien fue nombrado de manera precaria, es decir de forma interina mediante el decreto 1.802. Con ello se terminó resolviendo, aunque provisionalmente, la situación del Juez de Reparto con el nombramiento de Chaile como Juez de Río y de reparto de las acequias de Olmos y de Gallo, dado que:

es de indispensable necesidad, por cuanto, con la escasez de las lluvias, hay que mantener en turno el agua de dichas acequias y al no existir ninguna autoridad para su distribución se presentan a cada instante grave inconveniente, siendo este el que más sufre por esta causa ${ }^{85}$

La tardanza en el nombramiento de autoridades para la distribución del agua fue planteando otros problemas. Resulta interesante la nota que se enviara desde el Concejo Municipal el 11 de mayo de 1917. Esta nos indica sobre las "irregularidades" en la distribución y el por qué de la necesidad del nombramiento urgente de autoridades de riego. De acuerdo al presidente del Concejo Municipal cerrillano, el pedido de las autoridades se hacía a los efectos de que tanto los regantes de La Silleta como de Rosario de Lerma atajaban "caprichosamente" todo el caudal del agua de las acequias de Olmos y Gallo. Esta situación, de acuerdo al escrito, se planteaba porque todavía no habían sido nombrados los Jueces de rio y de Reparto. Tal realidad era generadora de un vacío en la administración del agua que se había provocado por la aplicación de la ordenanza. Además, porque tanto el municipio de Rosario de Lerma - de quien ya nos habíamos referido anteriormente - y el de La Silleta no reconocían al Sr. Ceferino Chaile como autoridad del agua. En este sentido, resulta importante destacar que quienes desconocían a las autoridades interpuestas por la provincia habían sido aquellos mismos funcionarios y ex funcionarios responsables de la

84 A.H.M.C., Acta de Oficios 1902-1919. Nota en reclamo de los abusos e incorrecciones del Juez Repartidor del Agua Don Telesfor Paz, 14 de junio de 1916.

85 A.H.M.C., Actas de Oficios, 1902-1919. Nota enviada al Ministro de Gobierno Don Rafael Zuviria solicitando se nombre Juez de Rio y Repartidor, 19 de enero de 1917. 
distribución del agua de las acequias de Olmos y de Gallo en tiempos previos a la aplicación de la ordenanza. Entre ellos se destacaron los señores Enrique Gutiérrez y Telésforo Paz - a quien ya se los había denunciado antes por abusos - y Máximo Kepes de Rosario de Lerma:

No escapará el elevado criterio de S.S. lo perjudicial y peligroso que resulta esta situación para los habitantes de este Departamento, y digo peligroso, por cuanto no sería dificil que, de continuar en este estado, los damnificados se vieran obligados a producir actitudes violentas a fin de conseguir el indispensable líquido a que legítimamente tienen derecho ${ }^{86}$

La frase es demostrativa de los alcances que tuvieron, en su momento, las irregularidades en torno al cumplimiento de la Ordenanza de Irrigación. La misma, como ya se dijo, había sido enviada por las autoridades de las cuatro Comisiones municipales en común acuerdo.

En síntesis, con estas referencias hemos podido avanzar en aquellos antecedentes normativos que han llevado a la institucionalización del manejo del agua en manos de la provincia. Resulta interesante denotar que más allá de las normas, hemos podido establecer, desde la mirada micro, los alcances de las mismas y la dinámica que se generó en un espacio local como el Departamento de Cerrillos. De esa manera, se advirtieron las reacciones de los regantes y de sus funcionarios frente a la provincialización del agua que permitió, por lo menos desde lo reglamentario, regularizar la situación hídrica en los departamentos de Cerrillos y Rosario de Lerma.

\section{Conclusiones}

Hasta aquí hemos podido hacer una revisión de los procesos de institucionalización del agua llevados a cabo por la Provincia de Salta en el Departamento de Cerrillos desde la segunda mitad del siglo XIX hasta 1921, para lo cual se avanzó con el análisis de las diversas normativas (Reglamentos, Códigos Rurales, Ordenanzas, etc.) que demuestran dichos procesos. La investigación nos permite, además, indagar no sólo

86 A.H.M.C., Actas de Oficios 1902-1919. Nota enviada al Ministro de Gobierno de la provincia reiterando nombramiento de funcionarios del agua, 11 de mayo de 1917. 
sobre los alcances de las políticas públicas alrededor del manejo del agua por parte del estado provincial en un departamento como Cerrillos; asimismo nos permite comprenderlas dentro del proceso de creación e imposición del orden estatal, tanto a nivel local y provincial como nacional. En este sentido, los aportes historiográficos ${ }^{87}$ que han permitido pensar la política de una manera menos determinista en relación a cómo se construye el orden estatal resultan interesantes insumos para enriquecer la presente investigación, dado que han posibilitado pensar la institucionalización del agua no como resultado de políticas unidireccionales, sino de instancias de conflictos, diálogos y hasta de adaptaciones de parte de las élites de Cerrillos y Rosario de Lerma. Esta perspectiva, que nos sirve para despojarnos de la idea de un Estado como un dispositivo institucional todopoderoso, ${ }^{88}$ ha permitido un enfoque distinto mostrándonos lo fértil que resulta pensar el Estado en plural.

Estos aportes nos permiten sostener que los procesos de institucionalización respecto del manejo del agua dados en el Departamento de Cerrillos no fueron del todo uniformes ni tuvieron la característica de ser efectivas, sino que estuvieron condicionados por el accionar de diversos actores sociales que desobedecían las nuevas formas de gobernabilidad. Es así que, con el objeto de ver un proceso social y político más amplio, hemos podido advertir que los intentos por provincializar el manejo del agua se tuvieron que someter a las disputas y tensiones entre las élites de Cerrillos y Rosario de Lerma y los diferentes sectores (Concejos Municipales, burócratas del agua, etc.) vinculados al recurso hídrico, generando tensiones identificables a través de diversos ejemplos a lo largo del período estudiado. De esa manera, siguiendo los escritos de Bohoslavsky \& Godoy Orellana, es evidente que no existió la unidireccionalidad en las políticas alrededor del agua sino una lucha en el sentido de "abajo hacia arriba", haciendo de los intentos por institucionalizar el agua un foco de resistencia encabezada por aquellos sectores que se creían los dueños del agua. Al respecto de esto último, no cabe dudas que las evidencias demuestran que la resistencia no fue llevada a cabo por sectores subalternos dado que estos carecían del control de la tierra y el agua, sino por miembros de las élites posicionados en reductos

87 Bohoslavsky \& Soprano 2010, Soprano 2008, Ortiz Borgia 2015, entre otros. 88 Soprano, 2008: 36. 
del poder político, tales como los Concejos Municipales o el Congreso. En este sentido, queda demostrado que en el caso analizado fueron las élites locales aquellas que desafiaron al orden estatal puesto que veían en la institucionalización un problema que les podía afectar sus privilegios y fueros coloniales sobre el agua. De acuerdo a Bohoslavsky \& Godoy Orellana, ${ }^{89}$ estas tampoco permanecieron ajenas a los desafíos del orden estatal puesto que desarrollaron formas en las que resistieron, aceptaron, negociaron y/o resignificaron el proceso de construcción e imposición del Estado. Es decir que, desde sus lógicas políticas, también contribuyeron en el logro de la estatización, aunque mediada por su intervención. En este sentido, las decisiones políticas y las políticas públicas alrededor del agua dadas en la provincia de Salta son el resultado de pujas y reposicionamientos permanentes y simultáneos, en el que participaron distintos actores sociales desde una posición política que les resultaba eficaz para la conservación de su hegemonía sobre un recurso estratégico frente a la transformación agraria de fines del siglo XIX y principios del XX.

Estos aportes, por otra parte, permiten sostener en base a nuestras evidencias y siguiendo la opinión de Ortiz Bergia, ${ }^{90}$ que estamos “... frente a una realidad plural que posee múltiples facetas, características y mecanismos de acción, al cual es necesario examinar desde adentro para explorar sus rasgos y las transformaciones de su estructura, sus agentes y los complejos procesos de institucionalización de sus intervenciones...”. Del abordaje de las diferentes acciones llevadas a cabo por el estado provincial respecto al manejo del agua entre 1901 y 1921, hemos encontrado diversas referencias sobre un período que se caracteriza por el carácter complejo de la institucionalización del agua a nivel provincial. A través del Código Rural de 1903, de la Ordenanza de la Quebrada del Río Toro (1914) y de un breve análisis del Proyecto de Ley de Irrigación de 1901 y de la Ley de Irrigación $n^{\circ} 1.633$, hemos construido la trayectoria de un proceso que si bien plantea un camino hacia una institucionalización provincial del manejo del agua, sus resultados fueron más bien inconclusos dado que se advierten disrupciones provocadas por las confluencias de diversas intervenciones ajenas al estado. En este sentido, quedó de manifiesto que, si bien las élites locales pudieron haber acompañado

89 Bohoslavsky \& Orellana, 2008: 6.

90 Ortiz Bergia, 2015: 60. 
el proceso, en la medida que sus intereses se vieron afectados por el hecho de perder el control sobre el agua, comenzaron a obstaculizar la concreción de las mismas. Nuestra evidencia más elocuente, trata de la renuncia a las bancas de la Legislatura y el vacío de poder creado por la oposición contra el gobierno del Dr. Joaquín Castellanos. Como ya se planteó, oportunamente el avance contra la hegemonía de los dueños de las tierras y de las aguas mediante leyes como la de irrigación trajo como consecuencia la intervención del gobierno provincial, dilatando la discusión sobre la ley de aguas por otras dos décadas. De esa manera, los sectores hegemónicos conservadores lograron mantener intactos sus privilegios sobre un recurso que consideraban como privado moldeando los procesos de institucionalización e incidiendo en las políticas públicas alrededor del agua. Con lo dicho queda claro que los intentos por centralizar el manejo de agua se enfrentaron, como los sostiene Ortiz Bergia, a condiciones materiales que limitaron su implementación, como la debilidad del estado, el escaso personal, la anuencia de los burócratas del agua con la élite local y la falta de financiamiento de las estructuras gubernamentales locales como es el caso de los municipios.

Por último, esta investigación ha tratado de agregarle un matiz a las investigaciones existentes que vuelcan su mirada al problema de la construcción del estado. Es así que desde la mirada de la institucionalización del agua en la provincia de Salta mediante un estudio de caso, queda en evidencia que no sólo hay que relativizar las intervenciones del estado, pues, como lo sostienen algunos autores estamos frente a una entidad estatal que durante ese período se nos aparece como "un gigante con pie de barro", 91 sino que, es pertinente pensar en las limitadas capacidades del estado en la implementación de las políticas públicas. Referido a nuestro abordaje, por ejemplo, queda demostrado que si bien la provincia se fue haciendo cargo del manejo del agua en su parte técnica y normativa, las actitudes de parte de algunos regantes locales nos llevan a pensar en la debilidad burocrática de un estado provincial que tuvo que lidiar con los intereses de una élite enquistada en reductos de poder local y provincial y dueña de los recursos naturales. Esta perspectiva, señalada por Ortíz Bergia, ${ }^{92}$ nos

91 Bohoslavsky \& Orellana; 2008, Ortiz Bergia, 2015.

92 Ortiz Bergia, 2015: 77. 
D. M. Ontivero $26 / 27:$ pp.103-146 Cuadernos de Historia. Serie economía y sociedad

habla de la precariedad que presidió el accionar estatal y las limitadas capacidades que tuvieron los organismos estatales para garantizar el cumplimiento de las normativas. 


\section{FUENTES}

Actas del Concejo municipal, 1856-1920 en Archivo Histórico Municipal de Cerrillos, (A.H.M.C.)

\section{BIBLIOGRAFÍA}

Aguirre González, N. A. Palerm Viqueira, J. \& Montes Hernández, R. 2010, "Historia del manejo social del agua de la Sub- Cuenca del Río Tejalpa, Estado de México" en Primer Congreso Red de Investigadores Sociales sobre el Agua. México.

Ashur Mas, D. 2004, "Salta: La institucionalización del agua” en Hoops, T. \& Ashur, E. La crisis del agua en Salta. Entre la sequía y la inundación, Center for Latin American and Caribean Studies- Universidad Estatal de Michigan- Fundación CAPACITAR, Salta.

Bohoslavsky, E. \& Godoy Orellana, M. 2008, "Ideas para la historiografía de la política y el Estado en Argentina y Chile, 1840-1930” en Polis. Revista Latinoamericana, Núm. 19.

Castañeda González, R. 2004, “La centralización de un sistema de distribución: el reparto de agua del rio Cantarranas, Puebla, 1890-1930" en Boletín Archivo Histórico del Agua: Organizaciones auto-gestivas para el riego, Nueva Época, Año 9, pp. 45 a 56.

Comba, A. 2007, Historias (pocos conocidas) del agua en Tucumán. San Miguel de Tucumán.

Cornejo, A. 1947, El derecho privado en la legislación Patria de Salta, Coni, Buenos Aires.

Cornejo, A. 1980, Contribución a la Historia del Derecho de Aguas de Salta, Publicación del Instituto de San Felipe y Santiago de Estudios Históricos de Salta, Salta.

Escobar Ohmstede, A. 2013, "Cambios en el paisaje hidroagrario. ¿La Revolución un detonante?: el caso de San Luis de Potosí (19101940)” en Relaciones, Núm. 136, pp. 265 a 315.

Figueroa, R. Á. 2017, "Evolución de la legislación de aguas en la Provincia de Salta" en el IV Congreso Nacional de Derecho agrario provincial, UCA, Salta.

Genini, G. 2000, “Riego, Estado y Legislación en San Juan 1850-1914" en Scripta Nova. Revista electrónica de Geografía y Ciencias Sociales, Núm. 66.
Giménez Zapiola, E. 1918, La intervención de Salta, Buenos Aires.

Gómez Serrano, J. 2013, “La administración de agua en el tránsito del Antigua Régimen a la República. Aguascalientes, 1821-1835” en Relaciones, Núm. 136, pp. 187 a 222.

Hernández Aparicio, N. 2020, “Agua y política: Creación de la municipalidad y contexto de sanción del primer reglamento de aguas en San Salvador de Jujuy (1852-1860) en Quid, Núm. 16, pp. 191 a 215.

Kauffer Michel, E. 2010, "Hidropolítica del Candelaria: del análisis de la Cuenca al estudio de las interacciones entre el río y la sociedad ribereña" en Relaciones, Núm. 124.

Latzina, F. 1899, Diccionario geográfico argentino. Disponible en: http://www.bibliotecadigital.gob.ar/items/sho w/1264 [Consulta: 17 de junio de 2021].

Martín, F. Rojas, F. \& Saldo, L. 2010, “Domar el agua para gobernar. Concepciones sociopolíticas sobre la naturaleza y la sociedad en contextos de consolidación del Estado provincial mendocino hacia finales del siglo XIX y principios del XX" en Anuario del Centro de Estudios Históricos "Prof. Carlos S. A. Segreti" Córdoba (Argentina), año 10, Núm. 10, pp. 159 a 186.

Mazabel, D. 2007, “Apuntes sobre organización social y riego en México" en Revista de Antropología Experimental, Núm. 7.

Miranda, O. 2009, "Trayectoria tecnológica y uso del agua en la Agricultura argentina bajo riego" en Revista Agricultura, Sociedad y Desarrollo. Vol. 6, Núm. 5.

Millón, R. Hall, C. \& Díaz, M. 1997, “El conflicto en el sistema de riego del Teotihuacán moderno" en Martínez Saldaña, T. \& Palerm Viqueira, J. (eds.) Antología sobre pequeño riego. Vol. I, Colegio de Posgraduados, México, pp. 89 a 145.

Ojeda, G. 1929, Recopilación ordenada de las leyes de la provincia de Salta y sus decretos reglamentarios. Talleres Gráficos C. Velarde, Salta.

Ortiz Bergia, M. J. 2015, "El Estado en el interior nacional en la primera mitad del siglo XX. Aproximaciones historiográficas a un objeto en constante revisión" en Estudios Sociales del Estado, Vol. 1, Núm. 1. 
D. M. Ontivero

26/27: pp.103-146

Cuadernos de Historia. Serie economía y sociedad

Palerm Viqueira, J. 2000, “Organización social y agricultura" en Martínez Saldaña, T. \& Palerm Viqueira, J. (Eds.) Antología sobre pequeño riego, Volumen II, Colegio de Posgraduados/Plaza y Valdéz, México.

Palerm Viquiera, J. 2003, "Legislación de aguas en el siglo XX, el papel de las organizaciones de usuarios en la aplicación de reglamentos y en la administración de los Distritos de Riego" en el $51^{\circ}$ Congreso Internacional de Americanistas, Santiago de Chile.

Ontivero, D. M. 2018, "Procesos de institucionalización del agua a través de los reglamentos de riego: el caso de Cerrillos a fines del siglo XIX (Provincia de Salta, Argentina)" en Cuadernos de Humanidades, Núm. 29, pp. 177 a 200.

Ontivero, D. M. 2019a, "El problema de la irrigación en Cerrillos y Rosario de Lerma a la luz de la hidropolítica (1857-1886)" en Revista Notas Históricas y Geográficas, Núm. 22, pp. 32 a 64.

Ontivero, D. M. 2019b, “Los conflictos por el agua durante la primera coyuntura hacia el manejo institucionalizado del agua. El caso de Cerrillos y Rosario de Lerma (Salta, Argentina entre 1857 y 1886)" en Revista Escuela de Historia, Núm. 17, Vol. 1.

Oré Vélez, M. T. 2005, Agua común y Usos privados: riego, estado y conflictos en la Acbirana del Inca, Fondo Editorial de la Pontificia Universidad Católica del Perú, Lima.

Ortiz Bergia, M. J. 2015, “El Estado en el interior nacional en la primera mitad del siglo XX. Aproximaciones historiográficas a $\mathrm{n}$ objeto en constante revisión" en Estudios Sociales del Estado, Vol. 1, Núm. 1, pp. 59 a 85.

Osorio, I. 2004, "Del repartimiento a la reglamentación la distribución de las aguas del Río Cuautitlán, 1762, 1914 y 1929” en Palerm Viqueira, J. (coord.), Sandre, I. Rodríguez Haros, B. \& Duana Caletteet, N. (eds.) Catálogo de Reglamentos de Agua en México, Siglo XX, AHA/ CIESAS/ CNA 3, México.

Rossi, M. C. \& Bandazo, G. 2016, "Gestión del riego en las llanuras argentinas. Poderes locales y provinciales en perspectiva comparada: Santiago del Estero y Buenos Aires entre la segunda mitad del siglo XIX y 1915" en el Congreso LatinoAmericano de Historia Económica (CLADHE V), Universidad de Sao Pablo, Sao Pablo.
Saravia, L. A. 2000. Salta. Esplendores y Ocasos (El Progreso Económico como racionalización), Gofica Editora, Salta.

Schlech, E. 1914, Salta y sus riquezas. Apuntes Económicosy Estadísticos. Buenos Aires.

Soprano, G. 2007 "Del Estado en singular al Estado en plural: Contribución para una historia social de las agencias estatales en la Argentina" en Cuestiones de Sociología, Núm. 4, 19 a 48.

Tasso, A. 2003-2004, "Un caso de expansión agraria capitalista seguido por depresión. Santiago del Estero, 1879-1940" en Población y Sociedad, Núm. 10/11, pp. 109 a 136.

Wauters, C. 1908, Irrigación en el Valle de Lerma. Informe General Preliminar, Imprenta de Coni Hermanos, Buenos Aires. 